\title{
Estimating the Term Structure of Commodity Market Preferences
}

DOI:

10.1016/j.ejor.2019.10.009

Document Version

Accepted author manuscript

Link to publication record in Manchester Research Explorer

\section{Citation for published version (APA):}

Christodoulakis, G. (2019). Estimating the Term Structure of Commodity Market Preferences. European Journal of Operational Research, 282(3), 1146-1163. https://doi.org/10.1016/j.ejor.2019.10.009

\section{Published in:}

European Journal of Operational Research

\section{Citing this paper}

Please note that where the full-text provided on Manchester Research Explorer is the Author Accepted Manuscript or Proof version this may differ from the final Published version. If citing, it is advised that you check and use the publisher's definitive version.

\section{General rights}

Copyright and moral rights for the publications made accessible in the Research Explorer are retained by the authors and/or other copyright owners and it is a condition of accessing publications that users recognise and abide by the legal requirements associated with these rights.

\section{Takedown policy}

If you believe that this document breaches copyright please refer to the University of Manchester's Takedown Procedures [http://man.ac.uk/04Y6Bo] or contact uml.scholarlycommunications@manchester.ac.uk providing relevant details, so we can investigate your claim.

\section{OPEN ACCESS}




\title{
Estimating the Term Structure of Commodity Market Preferences
}

\author{
George Christodoulakis \\ Alliance Manchester Business School, University of Manchester \\ Booth Street West, Manchester M15 6PB, UK, \\ Email: george.christodoulakis (at) manchester.ac.uk, \\ Tel +44-161-30 66 404, Fax 0044-161-275
}

\begin{abstract}
The commodity futures curve is viewed as a market-based path forecast, a term structure, optimizing multivariate loss preferences. Based on the forecast decision setting, we apply estimation of flexible multivariate loss functions, which reveal the preference term structure along the futures curve, which can be flat, smoothly sloping or oscillating, rotating among optimism, pessimism and symmetry. Evidence from the thirty main world commodities around the global crisis period, accommodates the futures curve forecast rationality questioned in the literature, suggesting the presence of joint preference asymmetries for longer maturities and symmetries for shorter ones. This reveals joint optimistic preferences for most commodities until 2004 , evolving into oscillating preferences rotating within the term structure from symmetry to pessimism and optimism in 2005-2008 and finally back to weaker optimism until 2013.
\end{abstract}

Keywords: (B) Finance; Commodity Futures; Forecast Decision, Loss Functions; Optimism; Preferences 


\section{Introduction}

Commodities constitute a major asset universe, with established two-way links to real economic activity as shown by Hamilton (2009) and Yang (2013), but also to financial assets as shown by Hong and Yogo (2012), influencing a broad set of forward-looking economic decisions ranging from consumption to investment portfolio allocations. Commodity futures curves are often viewed as market-based forecasts for the evolution of spot prices in the future, see Fama and French (1987), and are included in both private decisions and formal policy making processes, see Chen et al (2009). As an example, the Monetary Policy Committee of the Bank of England assumes that oil prices follow the path projected by the futures market in order to decide its central forecasts for CPI and GDP growth, see Nixon and Smith (2012).

By construction, futures prices target the spot prices of the underlying commodities on maturity date, and as they approach maturity futures and spot prices converge until coincidence. The conditions under which commodity futures prices constitute (or not) market-based forecasts and their predictive power, have been discussed in the literature extensively since the early work of Carter et al (1983), Hazuka (1984) and French (1986), but with little agreement. Still, recent evidence on oil futures prices provide rather poor evidence for their out-of-sample predictive ability, see Laws and Thompson (2004), while for other commodities the results are much more supportive, see for example Reeve and Vigfusson (2011). These views are often based on the standard approach linking predictability to market efficiency, which under rational expectations dictates that futures prices should constitute unbiased predictors of the spot price in the future. In this respect, conventional tests for market efficiency utilise univariate regressions, see Fama and French (1987) and Alquist and Kilian (2010), essentially advocating the use of conventional statistics such as the mean error and mean squared error which reflect symmetric preferences for the forecast decision maker, see also Menezes et al (2000) and Goyal and Welch, (2003), while Brenner and Kroner (1995) show under what conditions such tests should reject the null hypothesis of unbiasedness. Any such empirical approach is conditional on the maintained assumptions, including the preferences of the forecaster and as such, the the above studies ignore behavioural aspects in the decision-making context, such as the possibility of heterogeneous beliefs, see Joëts (2015), or the presence of asymmetric loss preferences for dependent forecast errors along the futures curve. Knowledge of such preference functions can have a tremendous impact on the structure of forecast optimality as well as on the evaluation criteria. 
In particular, in a decision-making problem allowing for the presence of asymmetric joint loss preferences, forecast optimality for the decision maker requires the presence of elements additional to the conditional expectation, involving the interaction between preferences, higher moments of the future distribution and the dependence to other assets. Thus, the conditional expectation is no longer an optimal forecast and tests based on this assumption often falsely conclude about the presence or the absence of market inefficiency or forecast irrationality. Elliott et al (2008) provide comprehensive evidence for the effects of asymmetric preferences on univariate tests of forecast rationality, see also Jarrow and Zhao (2006) for its analogue in portfolio optimization. The estimation of preference functions is generally a challenging problem, considered in a variety of decision making problems, see for example Blackmond-Laskey and Fischer (1987), Wakker and Deneffe (1996), Pennings and Smidts (2000), Pennings J and A Smidts (2003), Alghalith (2010), Halme and Kallio (2014), Brenner (2015), Feess et al (2016), Murphy and Brincke (2017) and Paravisini et al (2017).

In this paper we shall adopt a decision-making point of view, in which the futures markets for a commodity in various maturities are viewed as joint prediction markets, see Wolfers and Zitzewitz (2004), assuming that the efficient market hypothesis holds, so that the observed price of each commodity contract will be the best possible assessment of the available data. Thus, the market is viewed as a consensus forecast decision maker and the futures curve as a jointly determined path forecast, which optimizes multivariate flexible preferences, capturing both preference asymmetries and the dependence between forecast errors along the futures curve. Against the possible view that such preferences reflect a purely statistical estimation setting, rather than a financial decision making process, in the subsequent section we shall refer to the arguments of Granger and Machina (2006) who show how to derive the utility - based decision problem corresponding to a certain loss-function setting. As an example, one might think of a utility-maximizing commodity producer, whose hedging of price risk requires a daily settlement of his short futures position until maturity. Since the financing of margin requirements is costly especially when the position cumulates losses until maturity, but not so much in case of profits, the producer exhibits asymmetric preferences so that price under-forecasting along the futures curve results in heavier cost of such settlement versus an equal over-forecasting.

Observing time series of pricing errors for different futures maturities and assuming the existence of a generalized class of multivariate parametric forecast loss preferences, we estimate the parameters of the loss function and test for forecast rationality along the lines of 
the GMM procedure proposed by Komunjer and Owyang (2012). Our approach reveals the shape of preferences term structure along the futures curve, which can be flat, smoothly sloping, or oscillating, rotating among symmetry, optimism and pessimism. The shape of preferences term structure is shown to reflect the relationship of the average futures curve shape versus the spot price in the future. This is not the first time where term structure is considered in the context of financialised commodities; see for example applications on foreign exchange markets by Inci Ahmet Can (2004), De los Rios (2009) and Chen and Tsang (2013), although these studies do not deal with preference issues. Moreover, although the literature traditionally focuses on evidence for the energy markets, see Alquist and Kilian (2010), the interest is now being extended to broader commodity classes given the sharp movements in prices during the global credit crisis, the introduction of new large speculative funds in the market, see Singleton (2104) and Hamilton and Wu (2015), and the growth of non-energy futures markets. We consider the thirty main commodities constituting the universe of futures contracts for the six major world commodity indices classified in five sectors, namely agriculture, livestock, energy, industrial metals and precious metals. Our sample 2001 - 2013 focuses on a broad crisis period to include the high volatility years, suggesting the existence of a variety of preference term structures, revealing strong preference asymmetries for longer maturities and symmetries for shorter maturities. Moreover, in the presence of periodic price forecast breakdowns detected by applying the procedure of Giacomini and Rossi (2009), our results reveal preference term structures that are strongly optimistic for most commodities in 2001-2004, which evolve into oscillating preferences along the futures curves in 2005-2008 rotating from symmetry to pessimism and optimism, and finally back to general optimism in 2009-2013 but for a smaller number of commodities. Forecast rationality tests show that our framework accommodates the rationality of observed forecast errors and thus serves as a new approach for the advancement of forecasting and trading in commodity markets.

The paper is organised as follows. Section 2 presents the theoretical arguments and the empirical methodology on multivariate asymmetric loss preferences. Section 3 presents the data set and Section 4 our full-sample estimation results. Section 5 tests for possible price forecast breakdowns and Section 6 exhibits further empirical evidence in the presence of preference regime changes. Section 7 concludes.

\section{Estimating the Decision Maker's Joint Loss Preferences}


The recent developments in the estimation the forecaster's loss preferences essentially emerged from the criticism on the standard approaches assessing the optimality of observed forecasts. The standard approach to the study of the predictive content of commodity futures prices on the spot prices in the future has been introduced in early studies such as French (1986) and Fama and French (1987). Studies following the standard approach tend to link market efficiency to predictability, since the pricing error between the current futures price and the corresponding spot price in the future, constitutes both a portfolio profit or loss and a forecast error. This line of thought requires the pricing error to be on average zero to guarantee that both market efficiency and forecast rationality are maintained and is empirically tested through two simple linear regressions of the form

$$
\begin{gathered}
s_{t}-s_{t-s}=\alpha_{1}+\beta_{1}\left(f_{t-s, t}-s_{t-s}\right)+e_{1, t} \\
f_{t-s, t}-s_{t}=\alpha_{2}+\beta_{2}\left(f_{t-s, t}-s_{t-s}\right)+e_{2, t}
\end{gathered}
$$

where $s_{t}, s_{t-s}$ denote the current and $s$ periods back $(\log )$ spot price respectively, $f_{t-s, t}$ denotes the $(\log )$ futures price generated $s$ periods back that matures at time $t$ and $e_{t}$ represents a serially uncorrelated zero-mean random error, see Brenner and Kroner (1995) ${ }^{1}$. Under this setting and rational expectations, the composite null hypothesis of market efficiency and forecast rationality would require that $\alpha_{1}=0$ and $\beta_{1}=1$. More generally, positive $\beta_{1}$ means that basis $f_{t-s, t}-s_{t-s}$ observed at t-s contains information about the change in the spot price from t-s to $t$, or equivalently that futures price has power to forecast the spot rate in the future. Moreover, positive $\beta_{2}$ means the basis observed at t-s contains information about the premium $f_{t-s, t}-s_{t}$ to be realized at $\mathrm{t}$, which is evidence for the existence of time-varying expected premiums. Regressions (1a) and (1b) are subject to cross parameter restrictions, since the sum of their left side should equal the sum of their right side, therefore $\alpha_{1}+\alpha_{2}=0$ and $\beta_{1}+\beta_{2}=1$. Under this set of assumptions, the testing framework also implies that such a relationship should also hold between different futures maturities, so that we could write

$$
f_{t-1, t}-f_{t-s, t-s+1}=\alpha_{3}+\beta_{3}\left(f_{t-s, t}-f_{t-s, t-s+1}\right)+e_{3, t}
$$

\footnotetext{
${ }^{1}$ It can be shown that basis $f_{t-s, t}-s_{t-s}$ can be decomposed in two parts: (1) the cost-of-carry, that is the sum of storage costs less the convenience yield plus interest and risk premium and (2) the marking-to-market. As Fama and French (1987) note, the theory of storage provides an alternative but not a competing view of the basis.
} 
which provides a univariate iterative testing framework for the full term structure of the futures curve. However, this linear framework of equations $(1 a, b)$ and (1c) introduces a pathology in the testing procedures as it makes important implicit assumptions about how the forecast decision maker behaves and rational expectations are formed. First, the conditional expectation of $f_{t-s, t}-s_{t-s}$ (or $f_{t-s, t}-f_{t-s, t-s+1}$ ) can be an optimal predictor of the future spot price change $s_{t}-s_{t-s}$ (or $f_{t-1, t}-f_{t-s, t-s+1}$ ) only under symmetric forecast loss preferences, see Christoffersen and Diebold (1997). The presence of preference asymmetries, penalising asymmetrically positive vs negative forecast errors, would require the decision maker's optimal forecast to be composed of the conditionally expected future spot price plus a rational bias reflecting optimism or pessimism embedded in preference asymmetries. In this respect, estimation of the above two equations delivers in a large number of empirical cases spurious evidence suggesting the rejection of the composite null hypothesis, while this is just a reflection of the presence of neglected asymmetric loss preferences. Moreover, such an asymmetric preference forecast would cause a positive value for $\beta_{2}$, thus falsely showing as a time-varying expected premium. Second, the testing framework of equation (1c) ignores the correlation between forecast errors of the same variable for different horizons. The problem introduced by equations (1a,b) is effectively addressed by Elliott et al (2005) who contributed a general decision making - based univariate framework for the estimation of forecast loss preferences and testing of forecast rationality under flexible asymmetric loss functions, see also Christodoulakis and Mamatzakis (2009). The problem introduced by equation (1c) is more complex as it concerns a term structure or a path of forecasts, see Jordà and Marcellino (2010), and requires a formal multivariate treatment acknowledging the correlation structure between different horizon forecasts. This problem is addressed by Komunjer and Owyang (2012) who generalise the work of Elliott et al (2005) to a full multivariate setting, thus addressing the problems introduced by both equations (1a,b) and (1c) in a unified framework.

The possibility of empirical estimation of forecaster's loss preferences raises the fundamental question of whether such preferences reflect a purely economic decision making process or a facilitating artefact for statistical optimization. An economic decision maker's ultimate objective is not to eliminate expected loss, but rather to maximise expected utility or profits. Hence, as any forecast is destined to be subject to error, the loss arising from it simply reflects the loss in utility or profit due to missing perfect foresight. Accordingly, Granger and Machina (2006) show that it is possible to derive the family of underlying utility-based problems that generate a given loss function and its implicit restrictions. In perticular, the loss 
function $L$ ( ) induced by a decision problem based on utility function $U(s, \alpha)$ for a random variable $s \in S$ and a choice variable $\alpha \in A$, can be written as

$$
L\left(s_{r}, f\right) \equiv U\left(s_{r}, \alpha\left(s_{r}\right)\right)-U\left(s_{r}, \alpha(f)\right) \text { for all } s_{r} \text { and } f \in \mathrm{S}
$$

where $s_{r}$ and $f$ denote the realised and forecast value of $s$ respectively. Inessential transformations of the decision making problems on $U($ ) that do not change the implied loss function $L$ ( ) can lead to a family of decision problems consistent with $L$ ( ).

In this paper we shall follow the generalised decision making approach of Komunjer and Owyang (2012), viewing the set of different horizon price forecasts as a term structure or a path forecast, jointly determined. From a decision making point of view, we may think of the commodity market as a consensus forecaster, that is making joint decisions at each point in time for a set of commodity price forecasts for different horizons. Its decisions choose path forecasts that optimise multivariate asymmetric preferences on the losses occurring as a result of mis-forecasting along the futures curve. Let us denote $f_{t-s_{1}, t}, f_{t-s_{2}, t}, \ldots, f_{t-s_{N}, t}$ the set of commodity futures prices with maturity $s_{1}, s_{2}, \ldots, s_{N}$ periods-ahead respectively. For every maturity date $t$ we observe the spot price, $s_{t}$, thus leading to a vector $\mathbf{e}_{t}=\left(s_{t}-f_{t-s_{1}, t}, s_{t}-\right.$ $\left.f_{t-s_{2}, t,}, \ldots, s_{t}-f_{t-s_{N}, t}\right)^{\prime}$ of $N$ forecast errors. Following Komunjer and Owyang (2012) the preferences of the forecast decision maker take the form of a flexible multivariate loss function such as

$$
L_{N}\left(p, \boldsymbol{\tau}, \mathbf{e}_{t}\right)=\left(\left\|\mathbf{e}_{t}\right\|_{p}+\boldsymbol{\tau}^{\prime} \mathbf{e}_{t}\right)\left\|\mathbf{e}_{t}\right\|_{p}^{p-1}
$$

where $\mathbf{e}_{t}$ denotes our $N$-vector forecast error, $1 \leq p \leq \infty$ denotes a scalar parameter controlling the non-linearity and the $N$-vector $\boldsymbol{\tau}$ determines the degree of asymmetry with respect to over- or under-forecasting. The function (1d) exhibits a number of properties for the role of a multivariate loss function and nests a number of known special cases. The loss function is non-negative, continuous, taking the value of zero for $\boldsymbol{e}=\mathbf{0}$ and $\infty$ as $\|\mathbf{e}\|_{p} \rightarrow \infty$, while it is convex on $R^{\mathrm{N}}$. For $\boldsymbol{\tau}=\mathbf{0}$ the function exhibits symmetry and equals the sum of univariate losses $\left|e_{j}\right|^{p}$ for any value of parameter $p$. Moreover, for $\boldsymbol{\tau} \neq \mathbf{0}$ the function exhibits loss asymmetry, the nature of which is determined by both the magnitude and the direction of the deviation of loss from the symmetry case, whereas the magnitude is measured by $\|\mathbf{e}\|_{q}$, where $\frac{1}{q}+\frac{1}{p}=1$, and the direction is given by the sign of $\boldsymbol{\tau}$. Finally, for $N=1$ the function 
reduces to the univariate loss of Elliott et al (2005), for $N>1$ and $p=1$ the function exhibits additive reparability reducing to the sum of univariate losses, however for $p>1$ the function will lose the additive separable property. As a result, for $p>1$ optimality of multivariate forecasts would not generally imply optimality of univariate forecasts and vice versa.

In the presence of multivariate forecast error loss preferences (1d), given $p$ and $\tau$, the decision maker is assumed to construct the optimal multiple-step-ahead vector forecast of $\boldsymbol{s}_{t}$, $\boldsymbol{f}_{t}=\left(f_{t-s_{1}, t}, f_{t-s_{2}, t}, \ldots, f_{t-s_{N}, t}\right)^{\prime}=\Theta \boldsymbol{w}_{t-s_{N}}$, where $\Theta$ is an $N \times K$ matrix of unknown parameters and $\boldsymbol{w}_{t-s_{N}}$ is a $K \times 1$ vector observable variables known to the forecaster at $t-s_{N}$ thought to help forecast $\boldsymbol{s}_{t}$. The optimal forecast is constructed by solving

$$
\min _{\Theta} E\left[L\left(p, \boldsymbol{\tau}, \mathbf{e}_{\mathrm{t}}\right)\right]
$$

The first order optimality condition for the joint forecast is both necessary and sufficient, and can be shown that it takes the form

$$
E\left(p \mathbf{v}_{p}+\boldsymbol{\tau}\left\|\mathbf{e}_{t}\right\|_{p}^{p-1}+(p-1) \boldsymbol{\tau}^{\prime} \mathbf{e}_{t} \mathbf{v}_{p}\left\|\mathbf{e}_{t}\right\|_{p}^{-1} \mid I_{t}\right)=0
$$

where expectation $E($.$) is conditional on the time- t$ information set $I_{\mathrm{t}}$, $\mathbf{v}_{p}=\left(\operatorname{sgn}\left(e_{1}\right)\left|e_{1}\right|^{p-1} \quad \ldots \quad \operatorname{sgn}\left(e_{N}\right)\left|e_{N}\right|^{p-1}\right)^{\prime}$ and $\operatorname{sgn}(e)$ takes the values $(-1,1,0)$ for $(e<0, e>0$, $e=0$ ) respectively. Assuming the presence of a vector of $d$ instruments, $\mathbf{x}_{\mathrm{t}}$, which is a subvector of $\boldsymbol{w}$, then we can derive $\mathrm{N} \times d$ orthogonality conditions, $\mathbf{g}_{\boldsymbol{t}}$, which can be shown as

$$
\mathbf{g}_{t}=\left(p \mathbf{v}_{p}+\boldsymbol{\tau}\left\|\mathbf{e}_{t}\right\|_{p}^{p-1}+(p-1) \boldsymbol{\tau}^{\prime} \mathbf{e}_{t} \mathbf{v}_{p}\left\|\mathbf{e}_{t}\right\|_{p}^{-1}\right) \otimes \mathbf{x}_{t}
$$

If all the othogonality conditions are satisfied by the vector, $\tau$, then these conditions can be used to form a GMM estimator of $\tau$ such that

$$
\min _{\tau}\left[T^{-1} \sum \mathbf{g}_{t}\right] \hat{\mathbf{S}}^{-1}\left[T^{-1} \sum \mathbf{g}_{t}\right]
$$

Where matrix $\hat{\mathbf{S}}$ is a consistent estimate of $S$, and is given by $\hat{\mathbf{S}}=T^{-1} \sum \mathbf{g}_{t} \mathbf{g}_{t}^{\prime}$. The solution of the above problem delivers a GMM estimator of $\tau$ in closed form which takes the form

$$
\hat{\boldsymbol{\tau}}=-\left[\hat{\mathbf{B}}^{\prime} \hat{\mathbf{S}}^{-1} \hat{\mathbf{B}}\right]^{-1} \hat{\mathbf{B}}^{\prime} \hat{\mathbf{S}}^{-1} \hat{\mathbf{a}}
$$

where 


$$
\begin{aligned}
& \hat{\mathbf{B}}=T^{-1} \sum\left\|\mathbf{e}_{t}\right\|_{p}^{p-1}\left(\mathbf{I}_{N d} \otimes \mathbf{x}_{t}\right)+(p-1)\left\|\mathbf{e}_{t}\right\|_{p}^{-1}\left(\mathbf{v}_{p} \otimes \mathbf{x}_{t}\right) \mathbf{e}_{t}^{\prime} \\
& \hat{\mathbf{a}}=T^{-1} \sum p\left(\mathbf{v}_{p} \otimes \mathbf{x}_{t}\right)
\end{aligned}
$$

Similarly to the univariate case, note that matrix $S$ does depends on $\boldsymbol{\tau}$, which call for an iterative estimation. In the first iteration we assume $S=\boldsymbol{I}$ to extract the first rough estimate $\boldsymbol{\tau}_{\mathbf{1}}$, then in the second iteration $\boldsymbol{\tau}_{\mathbf{1}}$ is used to re-estimate $\boldsymbol{S}$ and extract the second estimate $\boldsymbol{\tau}_{\mathbf{2}}$, and so on until the estimate of matrix $\boldsymbol{S}$ stabilises and convergence is reached. Moreover, Komunjer and Owyang (2012) show that

$$
\sqrt{T}(\hat{\boldsymbol{\tau}}-\boldsymbol{\tau}) \stackrel{d}{\rightarrow} N\left(\mathbf{0},\left(\mathbf{B}^{\prime} \mathbf{S}^{-1} \mathbf{B}\right)^{-1}\right)
$$

Finally, as an analogue to the univariate test of Elliott et al (2005), when $d \gg>1$ produces a number of satisfied orthogonality conditions, then testing for over-identification essentially provides a procedure for a joint test of forecast rationality and asymmetric loss. Then, the associated $J$ statistic takes the form

$$
\hat{J}_{N}=T^{-1}\left[\sum \mathbf{g}_{t}\right] \hat{\mathbf{S}}^{-1}\left[\sum \mathbf{g}_{t}\right] \sim \mathrm{X}^{2} n(d-1)
$$

\section{The Commodity Universe of Major Futures Indices}

In this section we wish to present our data set as well as a number of empirical stylised facts that characterise the associated commodity markets in the respective period. The broad international commodity market includes a large and expanding number of commodities. The financialization of commodity price formation through " $\ldots$ the increasing role of financial motives, financial markets and financial actors in the operation of commodity markets ...", see UNCTAD (2011), reflects a global policy for the establishment of new organised commodity derivative markets across the globe, from Brazil and South Africa to India, China and Malaysia, see UNCTAD (2009). Commodity futures markets contribute to the efficiency and transparency of the price discovery mechanism and the management of risks. However a number of these markets are subject to liquidity constraints and, as a result, futures contracts may suffer from relatively less efficient price discovery. For this reason our data set will be focused on the universe of major world commodity markets. 
In particular, our dataset focuses on the full number of the constituent commodities of the six major indices ${ }^{2}$, covering thirty commodities across five sectors: energy, agriculture, livestock, industrial metals and precious metals. We use Bloomberg to collect generic (continuous) time series of futures price data from January 2001 to June 2013 with monthly frequency to cover a broad crisis period and include high volatility years. Bloomberg creates continuous time series for the prices of each maturity through rollover of contacts prior to their maturity. We opt for contract maturities that exhibit sufficiently large trading volume during our full sample period, which are one-, three-, six-, nine- and twelve-month maturities, although this choice is not fully supported by the availability of Bloomberg data for all contracts, see Table 1 for the relevant contract details. For the $i$-th commodity, $i=1, \ldots 30$, we construct a $N_{i} \times T$ matrix of price forecast errors which is a time series realisation of vector $\mathbf{e}_{t}$ as defined in (1c), where $N_{i}$ denotes the number of available futures contract maturities for the $i$-th commodity and $T$ denotes the number of monthly observations. Moreover, market liquidity issues led us to adopt at each time $t$ the nearest-to-maturity one-month futures contract as a proxy to the commodity spot price.

Table 1. Description of Commodity Futures Contracts

\begin{tabular}{clcccc}
\hline & Type & Exchange & $\begin{array}{c}\text { Bloomberg } \\
\text { Ticker }\end{array}$ & $\begin{array}{c}\text { Analysed Horizons } \\
\text { (in months) }\end{array}$ \\
\hline ENERGY & Crude Oil & WTI & NYMEX & CL & $1,3,6,9,12$ \\
Crude Oil & Brent & NYMEX & CO & $1,3,6,9,12$ \\
Gasoline & RBOB & NYMEX & XB & $1,3,6,9,12$ \\
Heating Oil & NY Harbour ULSD & NYMEX & HO & $1,3,6,9,12$ \\
Gas oil & ARA & ICE & QS & $1,3,6,9,12$ \\
Natural Gas & Henry Hub & NYMEX & NG & $1,3,6,9,12$ \\
\hline INDUSTRIAL METALS & & & & \\
Aluminium & Primary & LME & LA & $1,3,6,9,12$ \\
Copper & Primary & COMEX & HG & $1,3,6,9,12$ \\
Lead & Refined Pig Lead & LME & LL & $1,3,6,9,12$ \\
Nickel & Primary & LME & LN & $1,3,6,9,12$ \\
Zinc & Primary & LME & LX & $1,3,6,9,12$ \\
Tin & Refined Tin & LME & LT & $1,3,6,9,12$ \\
\hline
\end{tabular}

AGRICULTURE / SOFTS

\footnotetext{
${ }^{2}$ These are the Standard \& Poors - Goldman Sachs Commodity Index (S\&P GSCI), the Dow Jones - UBS Commodity Index,(DJ-UBSCI), the Rogers International Commodity Index (RICI), the Deutsche Bank Liquid Commodity Index (DBLCI), the Merrill Lynch Commodity index eXtra (MLCX) and the Thomson Reuters/Jefferies CRB Commodity Index (TR/J CRB).
} 


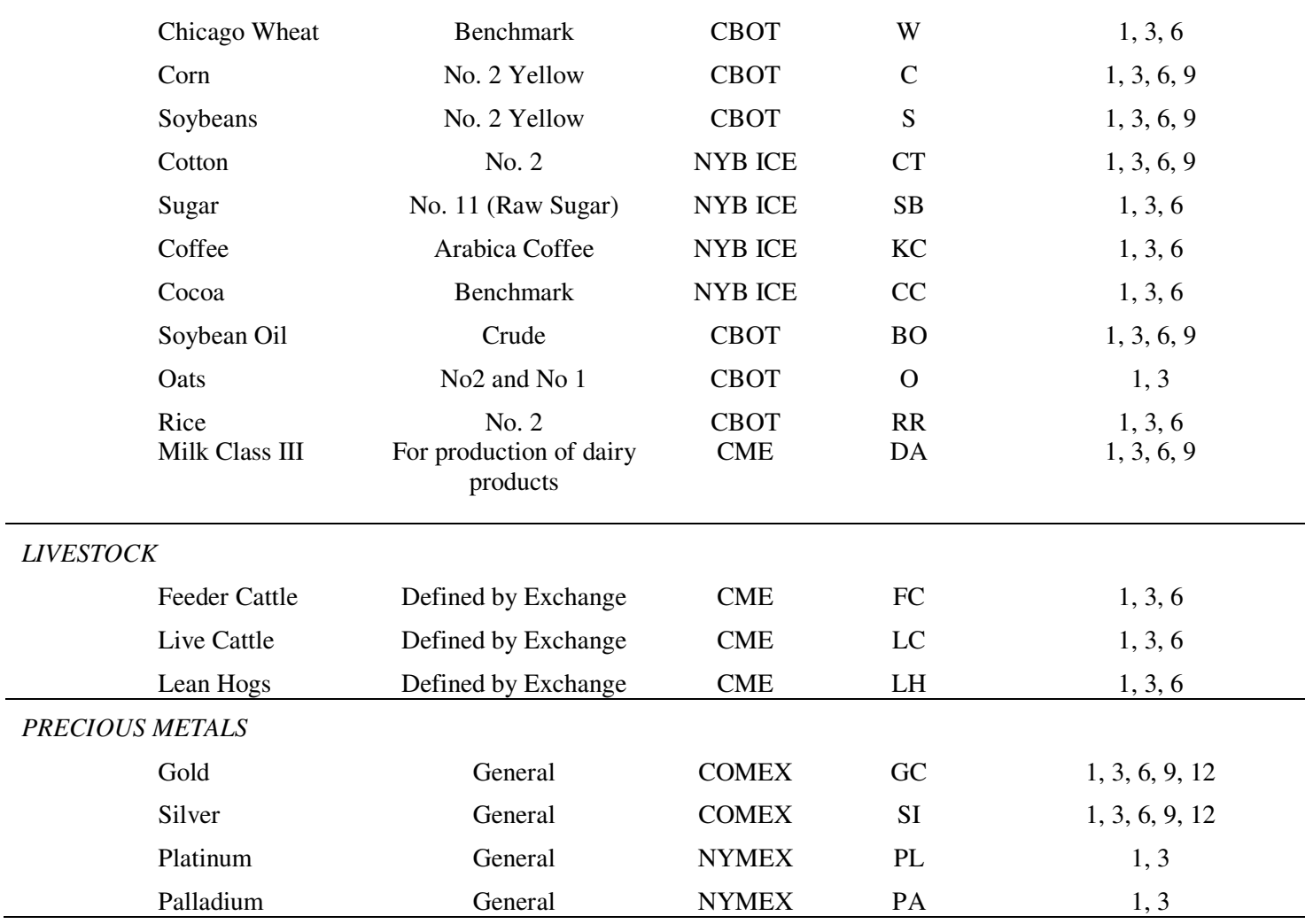

A graphical inspection of our average futures prices versus the corresponding average spot prices in the future, across commodities and over our full sample period, reveals three classes of futures curves with variants: Backwardation, Contango and ContangoBackwardation, which are presented in sections (a), (b) and (c) of Graph 1 respectively. Better understanding of the average futures curves versus the spot prices will help us to understand the sign and the size of the average forecast error as well as their evolution along different maturities and their implications for the associated joint loss preferences. Inspecting Graphs (1a) and (1b) we observe that Backwardation and Contango curves may be above, below or crossing the spot price line. Backwardation curve 1 exhibits decreasingly overpredicting expectations from the spot price as maturity gets longer, while curves 3 and 4 exhibit increasingly under-predicting expectations from the spot price as maturity gets longer, but curve 3 starts with agreement between futures and spot for short maturities at point A. Moreover, curve 2 exhibits the interesting case of expectations switch, in which for short maturities futures over-predict, then converge to the spot price at point B and subsequently under-predict for longer maturities. Contango curves 1 and 2 exhibit increasingly overpredicting expectations from the spot price as maturity gets longer, but curve 2 starts with 
agreement between futures and spot for short maturities at point A, while curve 4 exhibits decreasingly under-predicting expectations from the spot price as maturity gets longer. Moreover, curve 3 exhibits expectations switch, in which for short maturities futures underpredict, then converge to the spot price at point B and subsequently over-predict for longer maturities.

The third class of observed aggregate futures curves in our sample is depicted in Graph (1c) and constitutes a combination of Contango and Backwardation. The curves start at short maturities as Contango and then evolve into Backwardation for longer maturities. Curves 1, 2 and 3 exhibit increasingly over-predicting expectations, which are subsequently reduced, while curves 1 and 2 start with agreement between futures and spot for short maturities, see point A. Moreover, curve 1 exhibits expectations switch, in which for short maturities futures over-predict, then converge to the spot price at point B and subsequently under-predict for longer maturities. Finally, curve 4 exhibits decreasingly under-predicting expectation for short maturities, which evolve into agreement at point $\mathrm{C}$ and subsequently to increasing under-prediction for longer maturities.

Graph 1. Classes of Average Futures Curves, January 2001- June 2013
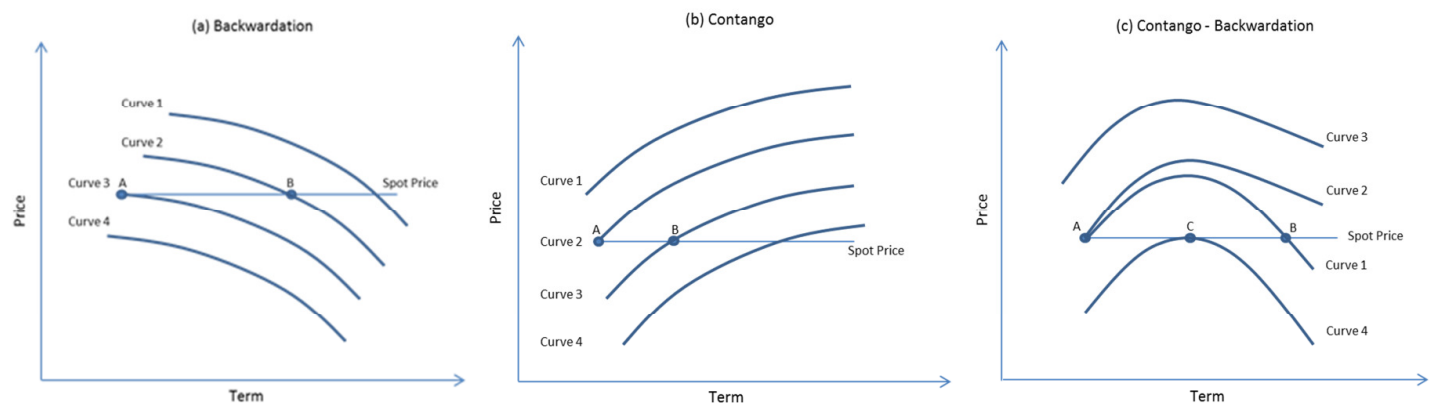

\section{Empirical Evidence}

Our empirical results for the full sample period are reported in Tables 2 and 3, where the upper part of each table reports estimates under quadratic loss function specification and the lower part concerns linear specification. We have performed GMM estimation for each contract using $d=N+1$ instruments, where $N$ denotes the number of available maturities, namely a constant and the first lag of the $N$ price forecast errors. In interpreting these results, let us recall that zero value of a loss function parameter signifies symmetric preferences for the respective variable, reflecting the same loss as a result of equal over- or underforecasting, positive value of a parameter signifies higher loss for over-forecasting and 
negative value of a parameter signifies higher loss for under-forecasting. Note that in the case of quadratic multivariate loss specification $(p=2)$, the degree of joint asymmetry is given by $\|\boldsymbol{\tau}\|_{2}$, while for the linear specification $(p=1)$ the function exhibits additive reparability reducing to the sum of univariate losses and the degree of joint asymmetry is given by $\|\boldsymbol{\tau}\|_{\infty}$. In our context, higher loss for over-forecasting (under-forecasting) would be interpreted as an aversion towards overvaluation (undervaluation) of commodities, an indication of pessimistic (imprudent or optimistic) preferences. However, the characterisation of higher aversion towards price under- (over-) forecasting as optimism (pessimism) essentially adopts an asset management perspective. This interpretation might change in different contexts, e.g. in policy making, in which a conservative or prudent view would require higher aversion towards under-forecasting. In the following we will keep the asset management perspective having in mind that interpretation might adapt in other applications.

Inspecting Tables 2 and 3 we observe that preference parameters differ significantly from zero typically for maturities longer than 3 months, while the strength of asymmetry increases with the length of maturity. The preference parameters for shorter maturities, in particular 1-month for agriculture and livestock and 1-, 3- or 6-month contracts for energy and metals, are typically not different from zero thus reflecting symmetric preferences. For $p$ $=2$, which is the case explicitly introducing price forecast error dependence, we observe seven different shapes in the term structure of preference parameters: flat (fully symmetric, fully optimistic, fully pessimistic), where preferences remain qualitatively the same for all maturities, sloping (symmetric-optimistic, symmetric-pessimistic), where preferences appear symmetric for short maturities and asymmetric for longer maturities and oscillating (symmetric-optimistic-pessimistic, symmetric-pessimistic-symmetric), where preference regimes tend to rotate across maturities. These patterns exactly reflect the relationship of the average shape of futures curve versus the average spot price in the future, over our sample period, as depicted in Graph 1. For example, consider curve 3 in Graph 1a, exhibiting agreement between futures and spot prices for short maturities and a widening underforecasting for longer maturities. This is reflected empirically on the estimated vector of preference parameters, $\boldsymbol{\tau}$, where elements corresponding to short maturities should not be statistically different from zero while elements corresponding to longer maturities take significant negative values, thus justifying a picture of upward sloping preferences evolving from symmetry to optimism along the futures curve. As a second example, consider curve 2 in Graph 1a, which exhibits over-forecasting of futures versus spot prices for short maturities, 
then converges to agreement for medium maturities, and subsequently diverges and exhibits a widening under-forecasting for longer maturities. The empirical reflection of this picture on the vector $\tau$, reveals statistically significant positive elements for short maturities, statistically zero elements for medium maturities and negative elements for longer maturities, thus justifying a picture of oscillating preferences evolving from optimism to symmetry and then pessimism along the futures curve. All curves presented in Graph 1 admit an analogous interpretation in terms of estimated preferences term structures captured by vector $\tau$.

Continuing inspection of Tables 2 and 3, our empirical evidence for agricultural commodities preferences are rather mixed, where we observe symmetric-optimistic preferences for Cotton and Milk and fully optimistic for Sugar, symmetric-pessimistic preferences for Wheat, Corn, Cotton and Coffee and fully pessimistic for Oat. Finally, we observe fully symmetric preferences for Cocoa, Soybean Oil and Rough Rice. For livestock commodities we observe symmetric optimistic preferences for Feeder Cattle and fully symmetric for Live Cattle and Lean Hogs. In the energy and metals markets optimism is the general behavioural characteristic, where we observe symmetric-optimistic preferences for twelve out of sixteen commodities, namely Crude Oil WTI, Crude Oil Brent, Gasoline, Heating Oil, Gas Oil, Aluminium, Copper, Lead, Nickel, Tin, Gold and Silver. Moreover, we observe fully symmetric preferences for Zinc, Platinum and Palladium and symmetricpessimistic preferences only for Natural Gas. Overall, our evidence for $\mathrm{p}=2$ in this section using the full sample of data, suggests there exists a smooth evolution of preferences across the futures curve which start as symmetric for short maturities and evolve into asymmetric ones for longer maturities, typically pessimistic for agricultural commodities and typically optimistic for energy and metals commodities. Moreover, our estimate for the $\mathrm{J}$ statistic rejects the null hypothesis of forecast rationality in all cases except of Platinum. This is not entirely surprising given the dramatic evolution of the commodity markets during the full sample period and the large standard errors of parameters for short maturities. The above results need to be compared with those for $\mathrm{p}=1$, where the loss function exhibits additive reparability reducing to the sum of univariate losses, thus losing the benefits of formally accounting for dependence between pricing forecast errors. 
Table 2. Multivariate Loss Estimation, Agricultural Commodities and Livestock, January 2001- June 2013

\begin{tabular}{|c|c|c|c|c|c|c|c|c|c|c|c|c|c|c|}
\hline & Wheat & Corn & Soybeans & Cotton & Sugar & Coffee & Cocoa & $\begin{array}{c}\text { Milk } \\
\text { Class III }\end{array}$ & $\begin{array}{c}\text { Soybean } \\
\text { Oil }\end{array}$ & Oats & $\begin{array}{l}\text { Rough } \\
\text { Rice }\end{array}$ & $\begin{array}{l}\text { Feeder } \\
\text { Cattle }\end{array}$ & $\begin{array}{c}\text { Live } \\
\text { Cattle }\end{array}$ & $\begin{array}{l}\text { Lean } \\
\text { Hogs }\end{array}$ \\
\hline \multicolumn{15}{|c|}{ Quadratic Specification $(p=2)$} \\
\hline \multirow[t]{2}{*}{$\tau_{1}$} & 0.26 & 0.17 & 0.05 & -0.08 & -0.42 & -0.45 & -0.31 & 0.00 & 0.11 & 0.70 & -0.32 & -0.00 & 0.02 & -0.64 \\
\hline & 0.37 & 0.26 & 0.42 & 0.42 & 0.31 & 0.48 & 0.56 & 0.14 & 0.30 & 0.01 & 0.61 & 0.45 & 0.53 & 0.48 \\
\hline \multirow[t]{2}{*}{$\tau_{2}$} & 0.52 & 0.38 & -0.10 & 0.25 & -0.59 & 0.02 & -0.40 & -0.06 & 0.14 & 0.71 & 0.17 & -0.20 & 0.26 & -0.11 \\
\hline & 0.31 & 0.32 & 0.53 & 0.43 & 0.20 & 0.54 & 0.55 & 0.33 & 0.38 & 0.02 & 0.64 & 0.67 & 0.72 & 0.57 \\
\hline \multirow[t]{2}{*}{$\tau_{3}$} & 0.73 & 0.56 & -0.43 & 0.41 & -0.61 & 0.66 & -0.48 & -0.19 & 0.03 & & 0.59 & -0.69 & 0.36 & -0.07 \\
\hline & 0.26 & 0.27 & 0.40 & 0.44 & 0.26 & 0.44 & 0.66 & 0.41 & 0.38 & & 0.67 & 0.51 & 0.88 & 0.62 \\
\hline \multirow[t]{2}{*}{$\tau_{4}$} & - & 0.56 & -0.65 & 0.58 & - & - & - & -0.24 & -0.19 & - & - & - & - & - \\
\hline & & 0.33 & 0.38 & 0.43 & & & & 0.41 & 0.44 & & & & & \\
\hline \multirow[t]{2}{*}{$\tau_{5}$} & - & - & - & - & - & - & - & -0.44 & -0.41 & - & - & - & - & - \\
\hline & & & & & & & & 0.39 & 0.45 & & & & & \\
\hline$J$ & 41.4 & 66.7 & 55.8 & 45.3 & 71.0 & 69.5 & 58.9 & 78.62 & 55.55 & 12 & 44.88 & 58.79 & 56.1 & 77.4 \\
\hline$\|\boldsymbol{\tau}\|_{2}$ & 0.89 & 0.87 & 0.65 & 0.58 & 0.94 & 0.66 & 0.00 & 0.44 & 0.00 & 0.99 & 0.000 & 0.69 & 0.00 & 0.00 \\
\hline \multicolumn{15}{|c|}{ Linear Specification $(p=1)$} \\
\hline \multirow[t]{2}{*}{$\tau_{1}$} & 0.48 & 0.48 & -0.01 & -0.12 & -0.85 & -0.50 & -0.47 & -0.00 & -0.04 & - & -0.43 & -0.12 & -0.06 & -0.35 \\
\hline & 0.89 & 0.83 & 0.95 & 0.94 & 0.61 & 0.76 & 0.89 & 0.88 & 0.85 & & 0.87 & 0.98 & 0.97 & 0.78 \\
\hline \multirow[t]{2}{*}{$\tau_{2}$} & 0.79 & 0.77 & -0.43 & 0.46 & -0.88 & 0.32 & -0.49 & -0.36 & -0.16 & - & 0.08 & -0.44 & 0.41 & 0.09 \\
\hline & 0.62 & 0.62 & 0.83 & 0.86 & 0.48 & 0.88 & 0.85 & 0.87 & 0.86 & & 0.90 & 0.88 & 0.91 & 0.85 \\
\hline \multirow[t]{2}{*}{$\tau_{3}$} & 0.88 & 0.85 & -0.62 & 0.60 & -0.89 & 0.66 & -0.42 & -0.62 & -0.20 & & 0.45 & -0.63 & 0.41 & -0.32 \\
\hline & 0.47 & 0.48 & 0.73 & 0.76 & 0.46 & 0.70 & 0.89 & 0.76 & 0.91 & & 0.80 & 0.73 & 0.90 & 0.82 \\
\hline \multirow[t]{2}{*}{$\tau_{4}$} & - & 0.81 & -0.72 & 0.59 & - & - & - & -0.69 & -0.28 & - & - & - & - & - \\
\hline & & 0.57 & 0.68 & 0.74 & & & & 0.70 & 0.84 & & & & & \\
\hline \multirow[t]{2}{*}{$\tau_{5}$} & - & - & - & - & - & - & - & -0.69 & -0.33 & - & - & - & - & - \\
\hline & & & & & & & & 0.69 & 0.82 & & & & & \\
\hline$J$ & 40.7 & 59.8 & 75.7 & 57.6 & 61.4 & 76.4 & 66.3 & 78.3 & 96.2 & & 70.3 & 76.2 & 69.7 & 97.3 \\
\hline$\|\boldsymbol{\tau}\|_{\infty}$ & 0.88 & 0.87 & 0.00 & 0.00 & 0.89 & 0.00 & 0.00 & 0.00 & 0.00 & & 0.00 & 0.00 & 0.00 & 0.00 \\
\hline
\end{tabular}
parameter corresponding to futures contract maturity $\mathrm{j}$. Bold numbers denote statistical significance in at least $10 \%$ level. The numbers below the estimated parameters are standard errors. J statistic is $X^{2}$ distributed with $\mathrm{N}(\mathrm{D}-1)$ degrees of freedom. The $\mathrm{X}^{2}$ critical values for 9,16 and 25 degrees of freedom at 5\% (1\%) level are 16.92 (21.67), 26.30 (32) and 37.20 (44) respectively. 
Table 3. Multivariate Loss Estimation, Energy, Industrial and Precious Metals, January 2001- June 2013

\begin{tabular}{|c|c|c|c|c|c|c|c|c|c|c|c|c|c|c|c|c|}
\hline & $\begin{array}{c}\text { Crude } \\
\text { Oil WTI }\end{array}$ & $\begin{array}{c}\text { Crude } \\
\text { Oil Brent }\end{array}$ & Gasoline & $\begin{array}{c}\text { Heating } \\
\text { Oil }\end{array}$ & $\begin{array}{c}\text { Natural } \\
\text { Gas }\end{array}$ & Gas Oil & Aluminium & Copper & Lead & Nickel & Zinc & Tin & Gold & Silver & Platinum & Palladium \\
\hline \multicolumn{17}{|c|}{ Quadratic Specification $(p=2)$} \\
\hline \multirow[t]{2}{*}{$\tau_{1}$} & 0.03 & 0.02 & 0.16 & -0.01 & 0.08 & 0.1 & 0.05 & 0.02 & -0.02 & -0.02 & 0.09 & -0.01 & -0.07 & -0.01 & -0.06 & 0.01 \\
\hline & 0.25 & 0.25 & 0.42 & 0.29 & 0.26 & 0.28 & 0.27 & 0.19 & 0.21 & 0.25 & 0.27 & 0.19 & 0.24 & 0.31 & 0.79 & 0.82 \\
\hline \multirow[t]{2}{*}{$\tau_{2}$} & -0.05 & -0.05 & 0.02 & -0.1 & 0.22 & -0.1 & 0.13 & -0.03 & -0.09 & -0.11 & 0.24 & -0.12 & -0.21 & -0.12 & -0.51 & -0.13 \\
\hline & 0.34 & 0.31 & 0.36 & 0.33 & 0.26 & 0.3 & 0.3 & 0.29 & 0.3 & 0.36 & 0.34 & 0.28 & 0.26 & 0.34 & 0.97 & 1.1 \\
\hline \multirow[t]{2}{*}{$\tau_{3}$} & -0.18 & -0.11 & -0.12 & -0.21 & 0.42 & -0.09 & 0.16 & -0.16 & -0.28 & -0.31 & 0.27 & -0.29 & -0.38 & -0.26 & - & - \\
\hline & 0.35 & 0.29 & 0.34 & 0.32 & 0.23 & 0.31 & 0.29 & 0.3 & 0.33 & 0.35 & 0.42 & 0.28 & 0.26 & 0.34 & & \\
\hline \multirow[t]{2}{*}{$\tau_{4}$} & -0.4 & -0.4 & -0.39 & -0.45 & 0.56 & -0.34 & -0.13 & -0.39 & -0.48 & -0.49 & 0.19 & -0.5 & -0.53 & -0.43 & - & - \\
\hline & 0.32 & 0.26 & 0.3 & 0.29 & 0.17 & 0.28 & 0.4 & 0.28 & 0.29 & 0.34 & 0.5 & 0.22 & 0.21 & 0.29 & & \\
\hline \multirow[t]{2}{*}{$\tau_{5}$} & -0.64 & -0.67 & -0.66 & -0.66 & 0.57 & -0.6 & -0.47 & -0.69 & -0.65 & -0.58 & 0.11 & -0.71 & -0.7 & -0.68 & - & - \\
\hline & 0.28 & 0.24 & 0.3 & 0.24 & 0.27 & 0.27 & 0.5 & 0.23 & 0.3 & 0.39 & 0.59 & 0.2 & 0.21 & 0.25 & & \\
\hline$J$ & 71 & 83 & 66 & 78 & 88 & 88 & 76 & 54 & 63 & 85 & 72 & 70 & 81 & 62 & 7.7 & 25 \\
\hline$\|\boldsymbol{\tau}\|_{2}$ & 0.40 & 0.78 & 0.76 & 0.79 & 0.90 & 0.68 & 0.47 & 0.79 & 0.80 & 0.75 & 0.00 & 0.86 & 0.95 & 0.80 & 0.00 & 0.00 \\
\hline \multicolumn{17}{|c|}{ Linear Specification $(p=1)$} \\
\hline \multirow[t]{2}{*}{$\tau_{1}$} & -0.28 & -0.4 & 0.08 & -0.13 & 0.28 & -0.08 & -0.01 & -0.21 & -0.4 & -0.25 & 0.36 & -0.31 & -0.34 & -0.19 & -0.2 & -0.09 \\
\hline & 0.87 & 0.85 & 0.89 & 0.94 & 0.94 & 0.92 & 0.93 & 0.89 & 0.89 & 0.93 & 0.92 & 0.91 & 0.9 & 0.89 & 0.98 & 0.99 \\
\hline \multirow[t]{2}{*}{$\tau_{2}$} & -0.46 & -0.58 & -0.19 & -0.31 & 0.72 & -0.47 & -0.07 & -0.45 & -0.58 & -0.47 & 0.45 & -0.7 & -0.7 & -0.43 & -0.57 & 0.05 \\
\hline & 0.82 & 0.77 & 0.82 & 0.85 & 0.72 & 0.76 & 0.89 & 0.84 & 0.81 & 0.78 & 0.85 & 0.72 & 0.74 & 0.86 & 0.82 & 0.99 \\
\hline \multirow[t]{2}{*}{$\tau_{3}$} & -0.58 & -0.59 & -0.54 & -0.54 & 0.76 & -0.59 & -0.26 & -0.63 & -0.68 & -0.56 & 0.4 & -0.82 & -0.85 & -0.56 & - & - \\
\hline & 0.74 & 0.73 & 0.75 & 0.79 & 0.67 & 0.78 & 0.82 & 0.74 & 0.73 & 0.75 & 0.82 & 0.56 & 0.56 & 0.8 & & \\
\hline \multirow[t]{2}{*}{$\tau_{4}$} & -0.62 & -0.73 & -0.74 & -0.68 & 0.85 & -0.72 & -0.36 & -0.72 & -0.7 & -0.54 & 0.47 & -0.83 & -0.91 & -0.68 & - & - \\
\hline & 0.69 & 0.6 & 0.64 & 0.61 & 0.56 & 0.63 & 0.83 & 0.63 & 0.69 & 0.74 & 0.87 & 0.56 & 0.44 & 0.67 & & \\
\hline \multirow[t]{2}{*}{$\tau_{5}$} & -0.67 & -0.73 & -0.68 & -0.7 & 0.84 & -0.72 & -0.43 & -0.73 & -0.71 & -0.67 & 0.47 & -0.89 & -0.94 & -0.76 & - & - \\
\hline & 0.63 & 0.57 & 0.7 & 0.56 & 0.52 & 0.59 & 0.82 & 0.56 & 0.65 & 0.7 & 0.85 & 0.45 & 0.34 & 0.56 & & \\
\hline$J$ & 70 & 75 & 68 & 68 & 74 & 73 & 78 & 68 & 74 & 89 & 89 & 75 & 73 & 73 & 25 & 53 \\
\hline$\|\boldsymbol{\tau}\|_{\infty}$ & 0.67 & 0.73 & 0.74 & 0.70 & 0.85 & 0.72 & 0.00 & 0.73 & 0.71 & 0.00 & 0.00 & 0.89 & 0.94 & 0.76 & 0.00 & 0.00 \\
\hline
\end{tabular}

Note: The table reports Komunjer and Owyang (2012) GMM estimation results for multivariate loss functions using $d=N+1$ instruments. $\boldsymbol{\tau}_{\mathrm{j}}, \mathrm{j}=1, \ldots, 5$ denotes the loss function parameter corresponding to futures contract maturity $\mathrm{j}$. Bold numbers denote statistical significance in at least $10 \%$ level. The numbers below the estimated parameters are standard errors. $\mathrm{J}$ statistic is $\mathrm{X}^{2}$ distributed with $\mathrm{N}(\mathrm{D}-1)$ degrees of freedom. The $\mathrm{X}^{2}$ critical values for 9, 16 and 25 degrees of freedom at 5\% (1\%) level are 16.92 (21.67), 26.30 (32) and 37.20 (44) respectively. 
We observe that the two estimates agree in twenty out of thirty commodity cases, while for the rest ten cases our estimates for $p=1$ typically fail to reveal the preference asymmetries in longer maturities, which are presented as fully symmetric preferences.

\section{Market Pricing Forecast Breakdown}

Our evidence in section 4 suggests that the market tends to exhibit asymmetric preferences for longer maturities and symmetric preferences for short maturities. Out of the 30 commodities, this is evident for 21 under quadratic loss function specification and for 14 for linear specification, while the rest do not exhibit statistically significant loss asymmetries. This picture concerns the full study period, from 2001 to 2013, thus reflecting an on average behavior over a sample of at least 150 months. It is indicative that loss preference parameter estimates for short maturities take values that are often away from zero (symmetric preferences) along with large standard errors. However, this period is marked primarily by the 2005-2008 commodity market turmoil as well as a number of unique political and economic events, which might have changed the structural behavior of the markets in the subsequent years, see also Bakshi et al (2017). Given the strongly developed links between commodity and financial markets ${ }^{3}$, where as Credit Suisse (2012) states the latter tend to “... oscillate periodically from over-exuberance to excessive pessimism and back again ...", we wish to examine possible heterogeneity in the behavior of commodity markets over time. We shall apply the methodology proposed by Giacomini and Rossi (2009) to test for forecast breakdowns in sequential sample periods. The presence of a forecast breakdown maybe due to various factors including changes in preferences. Detection of possible breakdowns of the commodity market could indicate possible changes in the underlying preferences, thus guiding re-estimation of the multivariate market loss preferences in the respective subperiods.

As in Giacomini and Rossi (2009), for each contract our time-series sample of $T$ pricing forecast errors is partitioned between $m$ in-sample and $n=T-m-s+1$ out-of-sample data points. Then we consider three competing price forecasting processes: (i) a fixed scheme, in which the in-sample part at time $t$ contains data indexed $1, \ldots, m$; (ii) a rolling scheme, in

\footnotetext{
${ }^{3}$ Although for long time it was widely believed that correlation between commodity and equity markets was low, see Gorton and Rouwenhorst (2006), it is now a well-established empirical fact that both commodity and financial markets are affected by demand-side shocks, thus capturing common risk factors increasing correlation especially in the growing presence of financial speculators, see Fattouh et al (2012).
} 
which the in-sample part at time $t$ contains data indexed $t-m+1, \ldots, t$; and last (iii) a recursive scheme, in which the in-sample part contains data indexed $1, \ldots, t$. To formally define forecast breakdown we consider the distance of the loss performance out-of sample versus in-sample, which is termed Surprise Loss. Let a variable $S L_{\mathrm{t}+\mathrm{s}}$ at time $t+s$ defined as the distance of the out-of-sample loss $L_{\mathrm{t}+\mathrm{s}}$ at time $t+s$ from the average in-sample loss $\bar{L}_{4}$ at time $t, S L_{t+s}=$ $L_{t+s}-\bar{L}_{t}$ for $t=m, \ldots T-s$. The out-of-sample loss is given by $L_{t+s}=L\left(s_{t+s}-f_{t, t+s}\right)$. The in-sample loss $\bar{L}_{4}$ is calculated over the in-sample data part as defined by the corresponding forecasting schemes: Fixed Scheme: $\bar{L}_{t}=\frac{1}{m} \sum_{j=1}^{m-s} L\left(s_{j+s}-f_{j+s}\right)$, Rolling Scheme: $\quad \bar{L}_{t}=\frac{1}{m} \sum_{j=t-m+1}^{t-s} L\left(s_{j+s}-f_{j+s}\right)$ and Recursive Scheme: $\bar{L}_{t}=\frac{1}{t} \sum_{j=1}^{t-s} L\left(s_{j+s}-\right.$ $\left.f_{j+s}\right)$. Then, the Surprise Loss will be on average $\overline{S L}_{m, n}=n^{-1} \sum_{t=m}^{T-s} S L_{t+s}$. If the predictive ability of the commodity futures price is maintained from the in-sample to the out-of-sample forecast, then we would expect the Surprise Loss on average not to differ significantly from zero. If this is not the case, then a forecast breakdown should have taken place. It is now possible to set up a null hypothesis of no forecast breakdown taking the form $H_{0}: \mathrm{E}\left(\overline{S L}_{m, n}\right)=$ 0 . It can be shown that the test statistic $t_{m, n, s}=\frac{\sqrt{n} \overline{S L}_{m, n}}{\widehat{\sigma}_{m, n}}$, where $\hat{\sigma}_{m, n}$ is given by Giacomini and Rossi (2009), section 2.6, is standard normally distributed. Then, under the null hypothesis of no forecast breakdown, a test of level $\alpha$ would reject the null hypothesis when it exceeds the value of the $(1-\alpha)$-th percentile of the standard normal distribution. We perform this testing procedure along our sample considering 11 possible braking points corresponding to multiples of 12 monthly observations. That is, the first braking point sets the in-sample sample $m=12$, the second sets $m=24$ and so forth. Our empirical results are presented in Tables 4-9 which report $p$-values of the forecast breakdown test for all commodities, across all available contact maturities and for 11 sequential possible braking points. It is important to note that these results do not provide information about the direction ${ }^{4}$ but rather detect a change of price forecast quality. The general view of our empirical evidence suggests that the null hypothesis of no pricing forecast breakdown tends to be more often rejected during the first four or five years as well as during the last few years of our sample period. This suggests that when the period of commodity market turbulence is fully included in either of the in- or the out-of-sample data set a pricing forecast breakdown is

\footnotetext{
${ }^{4}$ Detection of forecast breakdown may reflect an improvement or a deterioration of loss, while detection of no forecast breakdown may reflect no change of loss in situations of either advanced or poor market price forecast performance.
} 
Table 4, Forecast Breakdown Tests, Agricultural Commodities - I

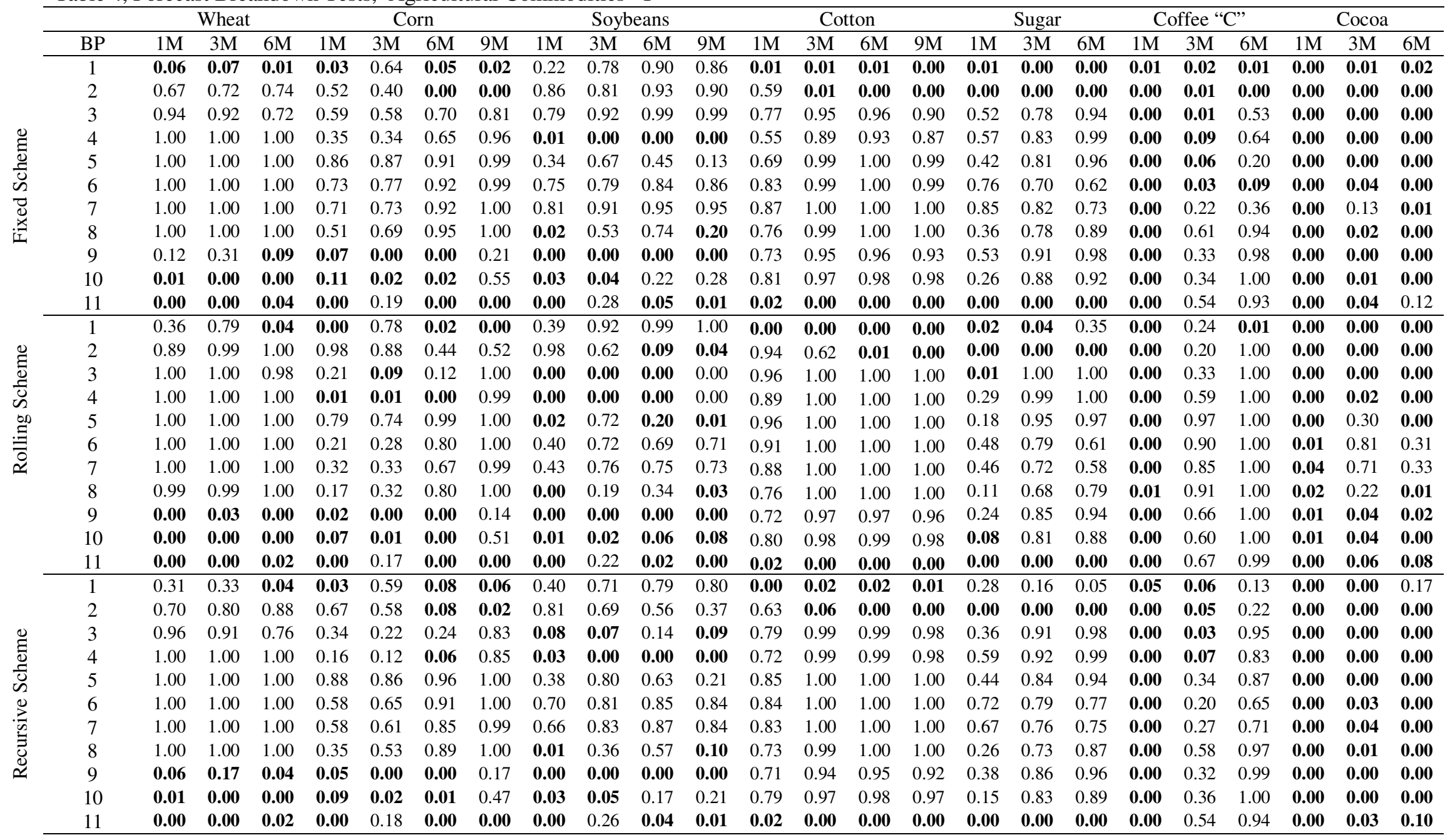


Table 5, Forecast Breakdown Tests, Agricultural Commodities - II

\begin{tabular}{|c|c|c|c|c|c|c|c|c|c|c|c|c|c|c|c|c|c|c|c|c|c|c|c|c|}
\hline & \multicolumn{5}{|c|}{ Milk Class III } & \multicolumn{5}{|c|}{ Soybean Oil } & \multicolumn{2}{|c|}{ Oats } & \multicolumn{3}{|c|}{ Rough Rice } & \multicolumn{3}{|c|}{ Feeder Cattle } & \multicolumn{3}{|c|}{ Live Cattle } & \multicolumn{3}{|c|}{ Lean Hogs } \\
\hline $\mathrm{BP}$ & $1 \mathrm{M}$ & $3 \mathrm{M}$ & $6 \mathrm{M}$ & $9 \mathrm{M}$ & $12 \mathrm{M}$ & $1 \mathrm{M}$ & $3 \mathrm{M}$ & $6 \mathrm{M}$ & $9 \mathrm{M}$ & $12 \mathrm{M}$ & $1 \mathrm{M}$ & $3 \mathrm{M}$ & $1 \mathrm{M}$ & $3 \mathrm{M}$ & $6 \mathrm{M}$ & $1 \mathrm{M}$ & $3 \mathrm{M}$ & $6 \mathrm{M}$ & $1 \mathrm{M}$ & $3 \mathrm{M}$ & $6 \mathrm{M}$ & $1 \mathrm{M}$ & $3 \mathrm{M}$ & $6 \mathrm{M}$ \\
\hline \multirow{6}{*}{ छี } & 0.92 & $\mathbf{0 . 0 0}$ & 0.03 & 0.01 & 0.01 & 0.01 & 0.02 & 0.02 & 0.01 & 0.00 & 1.00 & 0.97 & 0.27 & 0.00 & 0.00 & 0.92 & 0.98 & 0.99 & 0.01 & 0.02 & 0.14 & 0.18 & 0.69 & 0.89 \\
\hline & 0.96 & 0.01 & 0.00 & 0.00 & 0.03 & 0.00 & 0.00 & 0.00 & 0.00 & 0.00 & 1.00 & 1.00 & 0.03 & 0.00 & 0.00 & 0.92 & 0.99 & 1.00 & 0.00 & 0.00 & 0.00 & 0.80 & 0.98 & 0.94 \\
\hline & 0.92 & 0.09 & $\mathbf{0 . 0 0}$ & $\mathbf{0 . 0 0}$ & 0.03 & 0.00 & 0.00 & 0.01 & $\mathbf{0 . 0 3}$ & 0.02 & 1.00 & 1.00 & 0.00 & 0.01 & $\mathbf{0 . 0 0}$ & 0.97 & 0.99 & 1.00 & 0.20 & 0.00 & $\mathbf{0 . 0 0}$ & 0.28 & 0.98 & 0.97 \\
\hline & 0.98 & 0.00 & 0.00 & 0.00 & 0.03 & 0.00 & 0.00 & 0.00 & 0.00 & 0.01 & 1.00 & 1.00 & 0.00 & 0.03 & 0.00 & 0.13 & 0.00 & 0.14 & 0.00 & 0.00 & 0.00 & 0.14 & 0.51 & 0.00 \\
\hline & 0.99 & 0.10 & 0.21 & 0.73 & 0.90 & 0.27 & 0.84 & 0.92 & 0.92 & 0.94 & 0.99 & 1.00 & 0.01 & 0.43 & 0.02 & 0.24 & 0.03 & 0.01 & 0.00 & 0.00 & 0.14 & 0.58 & 0.47 & $\mathbf{0 . 0 0}$ \\
\hline & 1.00 & .15 & 0.49 & 0.87 & 0.98 & 0.64 & 0.91 & 0.97 & 0.99 & 1.00 & 1.00 & 1.00 & 0.02 & 0.86 & 0.59 & 0.42 & 0.03 & 0.01 & 0.00 & 0.00 & 0.09 & 0.76 & 0.02 & 0.00 \\
\hline 7 & 1.00 & 0.17 & 0.34 & 0.69 & 0.80 & 0.86 & 0.95 & 0.98 & 0.99 & 1.00 & 0.69 & 0.90 & 0.12 & 0.94 & 0.82 & 0.51 & 0.04 & 0.05 & 0.00 & 0.00 & 0.20 & 0.86 & 0.15 & 0.00 \\
\hline 8 & 0.97 & 0.31 & 0.50 & 0.85 & 0.92 & 0.00 & 0.00 & 0.19 & 0.60 & 0.81 & 0.52 & 0.76 & 0.16 & 0.60 & 0.11 & 0.46 & 0.15 & 0.25 & 0.00 & 0.00 & 0.60 & 0.76 & 0.61 & 0.02 \\
\hline 9 & 0.32 & 0.00 & 0.00 & 0.00 & 0.00 & 0.00 & 0.00 & 0.00 & 0.00 & 0.00 & 0.59 & 0.64 & 0.00 & 0.04 & 0.00 & 0.39 & 0.01 & 0.01 & 0.00 & 0.00 & 0.00 & 0.52 & 0.94 & 0.09 \\
\hline 10 & 0.38 & 0.07 & 0.00 & 0.00 & 0.00 & 0.00 & 0.00 & 0.00 & 0.00 & 0.00 & 0.53 & 0.52 & 0.00 & 0.01 & 0.00 & 0.63 & 0.10 & 0.21 & 0.00 & 0.00 & 0.00 & 0.06 & 0.88 & 0.68 \\
\hline 11 & $\mathbf{0 . 0 3}$ & 0.00 & 0.00 & 0.00 & 0.00 & 0.00 & 0.00 & 0.00 & 0.00 & 0.00 & 0.41 & 0.43 & 0.00 & 0.00 & 0.00 & 0.60 & 0.34 & 0.30 & 0.00 & 0.00 & 0.00 & 0.05 & 0.43 & 0.74 \\
\hline 1 & 00 & 0.00 & 0.01 & $\mathbf{0 . 0 0}$ & 0.00 & 0.00 & 0.01 & 0.00 & 0.06 & 0.0 & 1.00 & $1 .($ & 0.01 & $\mathbf{0 . 0 0}$ & $\mathbf{0 . 0 0}$ & 1.00 & 1.00 & 1.00 & $\mathbf{0 . 0 0}$ & 0.00 & 0.00 & 0.48 & 0.93 & 0.19 \\
\hline 2 & 1.00 & 0.00 & 0.00 & 0.00 & 0.00 & $\mathbf{0 . 0 0}$ & 0.00 & 0.00 & $\mathbf{0 . 0 0}$ & 0.00 & 1.00 & 1.00 & 0.00 & 0.00 & $\mathbf{0 . 0 0}$ & 0.86 & 0.90 & 0.97 & 0.00 & 0.00 & $\mathbf{0 . 0 0}$ & 0.00 & 0.51 & 0.87 \\
\hline 3 & 1.00 & 0.00 & $\mathbf{0 . 0 0}$ & $\mathbf{0 . 0 0}$ & 0.00 & 0.00 & $\mathbf{0 . 0 0}$ & 0.00 & 0.00 & 0.00 & 1.00 & 1.00 & 0.00 & $\mathbf{0 . 0 0}$ & $\mathbf{0 . 0 0}$ & 0.11 & 0.00 & 0.00 & 0.00 & 0.00 & $\mathbf{0 . 0 0}$ & 0.00 & 0.50 & $\mathbf{0 . 0 0}$ \\
\hline 4 & 1.00 & 0.00 & 0.00 & 0.00 & 0.00 & 0.00 & 0.00 & 0.00 & 0.00 & 0.01 & 1.00 & 1.00 & 0.00 & 0.08 & 0.00 & 0.05 & 0.00 & 0.00 & 0.00 & 0.00 & $\mathbf{0 . 0 0}$ & 0.33 & 0.49 & 0.00 \\
\hline 5 & 1.00 & .05 & 0.27 & 0.93 & 0.93 & 0.09 & 1.00 & 1.00 & 1.00 & 0.99 & 0.97 & 1.00 & 0.00 & 0.88 & 0.23 & 0.24 & 0.00 & 0.00 & 0.00 & 0.00 & 0.38 & 0.86 & 0.40 & 0.00 \\
\hline 6 & 1.00 & 05 & 0.23 & 0.64 & 0.80 & 0.57 & 0.93 & 0.97 & 0.98 & 0.9 & 0.96 & 1. & 0.00 & 0.97 & 0. & 0.47 & 0.00 & 0.00 & 0.00 & 0.00 & 0.05 & 0.76 & 0.17 & 0.00 \\
\hline 7 & 0.99 & 0.09 & 0.18 & 0.42 & 0.38 & 0.77 & 0.90 & 0.94 & 0.94 & 0.94 & 0.57 & 0.70 & 0.02 & 0.91 & 0.87 & 0.49 & 0.00 & 0.01 & 0.00 & 0.00 & 0.13 & 0.67 & 0.26 & 0.00 \\
\hline 8 & 0.94 & 0.17 & 0.29 & 0.72 & 0.74 & 0.00 & 0.00 & 0.01 & 0.15 & 0.42 & 0.48 & 0.64 & 0.02 & 0.38 & 0.06 & 0.43 & 0.03 & 0.05 & 0.00 & 0.00 & 0.50 & 0.56 & 0.62 & 0.08 \\
\hline 9 & 0.15 & 0.00 & 0.00 & 0.00 & 0.00 & 0.00 & 0.00 & 0.00 & 0.00 & 0.00 & 0.55 & 0.58 & 0.00 & 0.01 & $\mathbf{0 . 0 0}$ & 0.34 & 0.00 & 0.00 & 0.00 & 0.00 & $\mathbf{0 . 0 0}$ & 0.26 & 0.90 & 0.10 \\
\hline 10 & 0.25 & $\mathbf{0 . 0 3}$ & 0.00 & 0.00 & 0.00 & 0.00 & 0.00 & 0.00 & 0.00 & 0.0 & 0.50 & 0.4 & 0.00 & 0.00 & 0.1 & 0.56 & 0.04 & 0.08 & 0.00 & 0.00 & 0.00 & 0.02 & 0.82 & 0.62 \\
\hline 11 & 0.02 & 0.00 & $\mathbf{0 . 0 0}$ & 0.00 & 0.00 & 0.00 & 0.00 & 0.00 & $\mathbf{0 . 0 0}$ & 0.00 & 0.39 & 0.42 & $\mathbf{0 . 0 0}$ & $\mathbf{0 . 0 0}$ & $\mathbf{0 . 0 0}$ & 0.57 & 0.28 & 0.22 & 0.00 & 0.00 & 0.00 & 0.01 & 0.30 & 0.69 \\
\hline 1 & 0.88 & $\mathbf{0 . 0 0}$ & 0.05 & $\mathbf{0 . 0 0}$ & 0.01 & $\mathbf{0 . 0 0}$ & 0.06 & 0.06 & 0.13 & 0.04 & 0.90 & 0.82 & 0.33 & 0.01 & 0.01 & 0.93 & 0.97 & 0.97 & 0.20 & 0.10 & 0.13 & 0.40 & 0.61 & 0.59 \\
\hline 2 & 0.95 & 0.00 & 0.00 & 0.00 & $\mathbf{0 . 0 3}$ & $\mathbf{0 . 0 0}$ & 0.00 & $\mathbf{0 . 0 0}$ & 0.00 & 0.00 & 0.75 & 0.98 & 0.00 & 0.00 & $\mathbf{0 . 0 0}$ & 0.86 & 0.93 & 0.95 & 0.00 & 0.00 & $\mathbf{0 . 0 0}$ & 0.11 & 0.78 & 0.88 \\
\hline 3 & 0.97 & $\mathbf{0 . 0 0}$ & $\mathbf{0 . 0 0}$ & 0.00 & 0.00 & 0.00 & 0.00 & $\mathbf{0 . 0 0}$ & $\mathbf{0 . 0 0}$ & 0.0 & 1.00 & 1.0 & 0.00 & $\mathbf{0 . 0 0}$ & 0. & 0.58 & 0.14 & 0.21 & 0.00 & 0.00 & 0.00 & 0.04 & 0.84 & 0.13 \\
\hline 4 & 1.00 & 0.00 & 0.00 & 0.00 & 0.0 & 0.00 & 0.00 & 0.00 & 0.00 & 0.0 & 1.00 & 1.0 & 0.00 & 0.08 & 0.00 & 0.30 & 0.00 & 0.00 & 0.00 & 0.00 & 0.00 & 0.51 & 0.79 & 0.00 \\
\hline $\bar{c}$ & 1.00 & 0.10 & 0.23 & 0.75 & 0.89 & 0.22 & 0.93 & 0.97 & 0.97 & 0.96 & 0.90 & 1.00 & 0.01 & 0.64 & 0.04 & 0.43 & 0.03 & 0.04 & 0.00 & 0.00 & 0.27 & 0.78 & 0.51 & 0.00 \\
\hline 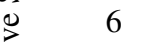 & 1.00 & 0.06 & 0.21 & 0.68 & 0.92 & 0.51 & 0.89 & 0.96 & 0.98 & 0.99 & 0.96 & 1.00 & 0.01 & 0.88 & 0.57 & 0.53 & 0.02 & 0.02 & 0.00 & 0.00 & 0.06 & 0.78 & 0.22 & 0.00 \\
\hline 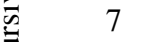 & 1.00 & 0.07 & 0.14 & 0.49 & 0.64 & 0.67 & 0.89 & 0.95 & 0.96 & 0.97 & 0.65 & 0.86 & 0.03 & 0.84 & 0.54 & 0.55 & 0.04 & 0.06 & 0.00 & 0.00 & 0.09 & 0.73 & 0.29 & 0.00 \\
\hline ]્ & 0.97 & 0.15 & 0.23 & 0.69 & 0.81 & 0.00 & 0.00 & 0.04 & 0.33 & 0. & 0.51 & 0.7 & 0.04 & 0.38 & 0. & 0.51 & 0.13 & 0.22 & 0.00 & 0.00 & 0.36 & 0.62 & 0.67 & 0.05 \\
\hline 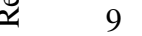 & 0.32 & 0.00 & 0.00 & 0.00 & 0.00 & $\mathbf{0 . 0 0}$ & 0.00 & $\mathbf{0 . 0 0}$ & 0.00 & 0.00 & 0.57 & 0.62 & 0.00 & 0.02 & 0. & 0.46 & 0.03 & 0.03 & 0.00 & 0.00 & $\mathbf{0 . 0 0}$ & 0.37 & 0.93 & 0.15 \\
\hline 10 & 0.37 & 0.04 & $\mathbf{0 . 0 0}$ & $\mathbf{0 . 0 0}$ & 0.00 & 0.00 & 0.00 & 0.00 & 0.00 & 0.00 & 0.51 & 0.50 & 0.00 & 0.00 & 0.00 & 0.65 & 0.15 & 0.26 & 0.00 & 0.00 & $\mathbf{0 . 0 0}$ & 0.04 & 0.87 & 0.68 \\
\hline 11 & $\mathbf{0 . 0 3}$ & 0.00 & 0.00 & 0.00 & 0.00 & 0.00 & 0.00 & 0.00 & 0.00 & 0.00 & 0.40 & 0.43 & 0.00 & 0.00 & 0.00 & 0.62 & 0.38 & 0.34 & 0.00 & 0.00 & 0.00 & 0.02 & 0.38 & 0.72 \\
\hline
\end{tabular}


Table 6, Forecast Breakdown Tests, Energy I

\begin{tabular}{|c|c|c|c|c|c|c|c|c|c|c|c|c|c|c|c|c|c|c|c|c|c|}
\hline & & \multicolumn{5}{|c|}{ Crude Oil WTI } & \multicolumn{5}{|c|}{ Crude Oil Brent } & \multicolumn{5}{|c|}{ Gasoline } & \multicolumn{5}{|c|}{ Heating Oil } \\
\hline & $\mathrm{BP}$ & $1 \mathrm{M}$ & $3 \mathrm{M}$ & $6 \mathrm{M}$ & $9 \mathrm{M}$ & $12 \mathrm{M}$ & $1 \mathrm{M}$ & $3 \mathrm{M}$ & $6 \mathrm{M}$ & $9 \mathrm{M}$ & $12 \mathrm{M}$ & $1 \mathrm{M}$ & $3 \mathrm{M}$ & $6 \mathrm{M}$ & $9 \mathrm{M}$ & $12 \mathrm{M}$ & $1 \mathrm{M}$ & $3 \mathrm{M}$ & $6 \mathrm{M}$ & $9 \mathrm{M}$ & $12 \mathrm{M}$ \\
\hline \multirow{11}{*}{ 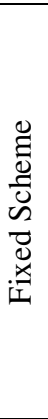 } & 1 & 0.02 & 0.01 & 0.01 & 0.03 & 0.00 & 0.01 & 0.01 & 0.00 & 0.01 & 0.00 & 0.01 & 0.00 & 0.00 & 0.00 & 0.00 & 0.04 & 0.01 & 0.00 & 0.01 & 0.01 \\
\hline & 2 & 0.25 & 0.05 & 0.00 & 0.00 & 0.00 & 0.00 & 0.00 & 0.00 & 0.00 & 0.07 & 0.00 & 0.00 & 0.00 & 0.00 & $\mathbf{0 . 0 0}$ & 0.02 & 0.00 & $\mathbf{0 . 0 0}$ & 0.00 & 0.03 \\
\hline & 3 & 0.05 & 0.00 & 0.01 & 0.00 & 0.00 & 0.00 & 0.00 & 0.16 & 0.27 & 0.05 & 0.00 & 0.00 & 0.03 & 0.00 & 0.00 & 0.00 & 0.00 & 0.00 & 0.01 & 0.00 \\
\hline & 4 & 0.01 & 0.00 & 0.00 & $\mathbf{0 . 0 0}$ & 0.00 & 0.00 & 0.00 & 0.00 & 0.00 & 0.00 & 0.00 & $\mathbf{0 . 0 0}$ & 0.00 & 0.00 & 0.00 & $\mathbf{0 . 0 0}$ & 0.00 & 0.00 & 0.00 & 0.00 \\
\hline & 5 & 0.84 & 0.95 & 0.97 & 0.88 & 0.35 & 0.64 & 0.94 & 0.97 & 0.94 & 0.63 & 0.01 & 0.66 & 0.95 & 0.85 & 0.14 & 0.04 & 0.82 & 0.94 & 0.86 & 0.47 \\
\hline & 6 & 0.89 & 0.97 & 0.99 & 0.97 & 0.72 & 0.65 & 0.96 & 0.99 & 0.98 & 0.87 & 0.00 & 0.57 & 0.95 & 0.91 & 0.27 & $\mathbf{0 . 0 3}$ & 0.87 & 0.97 & 0.96 & 0.78 \\
\hline & 7 & 0.88 & 0.97 & 0.98 & 0.97 & 0.88 & 0.72 & 0.96 & 0.99 & 0.99 & 0.96 & 0.02 & 0.71 & 0.96 & 0.95 & 0.66 & 0.16 & 0.92 & 0.98 & 0.97 & 0.93 \\
\hline & 8 & 0.02 & 0.00 & 0.62 & 0.71 & 0.21 & 0.00 & 0.00 & 0.60 & 0.81 & 0.44 & 0.00 & 0.00 & 0.29 & 0.66 & 0.10 & 0.00 & 0.00 & 0.50 & 0.78 & 0.51 \\
\hline & 9 & 0.00 & 0.00 & 0.00 & 0.00 & 0.00 & 0.00 & 0.00 & 0.00 & 0.00 & 0.00 & 0.00 & 0.00 & 0.00 & 0.00 & $\mathbf{0 . 0 0}$ & 0.00 & 0.00 & $\mathbf{0 . 0 0}$ & $\mathbf{0 . 0 0}$ & 0.00 \\
\hline & 10 & 0.01 & 0.00 & 0.00 & 0.00 & 0.00 & 0.00 & 0.00 & 0.00 & 0.00 & 0.00 & 0.00 & 0.00 & 0.00 & 0.00 & $\mathbf{0 . 0 0}$ & 0.00 & 0.00 & $\mathbf{0 . 0 0}$ & $\mathbf{0 . 0 0}$ & 0.00 \\
\hline & 11 & 0.01 & 0.00 & 0.00 & 0.00 & 0.00 & 0.00 & 0.00 & 0.00 & 0.00 & 0.00 & 0.03 & 0.00 & 0.00 & 0.00 & $\mathbf{0 . 0 0}$ & 0.00 & 0.00 & $\mathbf{0 . 0 0}$ & $\mathbf{0 . 0 0}$ & 0.00 \\
\hline \multirow{11}{*}{ 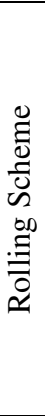 } & 1 & 0.00 & 0.00 & $\overline{0.00}$ & 0.04 & 0.18 & 0.00 & $\overline{0.00}$ & 0.00 & 0.06 & 0.17 & $\overline{0.00}$ & 0.00 & $\overline{0.00}$ & $\overline{0.00}$ & 0.02 & 0.00 & 0.00 & $\mathbf{0 . 0 0}$ & 0.01 & 0.09 \\
\hline & 2 & 0.00 & 0.00 & 0.00 & $\mathbf{0 . 0 0}$ & 0.00 & 0.00 & 0.00 & 0.00 & 0.00 & 0. & 0.00 & 0.00 & 0.00 & 0.00 & 0.00 & 0. & 0.00 & 0.00 & 0.00 & 0.00 \\
\hline & 3 & 0.00 & $\mathbf{0 . 0 0}$ & 0.00 & 0.00 & 0.00 & 0.00 & 0.00 & 0.00 & 0.00 & 0.00 & 0.00 & $\mathbf{0 . 0 0}$ & 0.00 & 0.00 & $\mathbf{0 . 0 0}$ & $\mathbf{0 . 0 0}$ & 0.00 & $\mathbf{0 . 0 0}$ & $\mathbf{0 . 0 0}$ & $\mathbf{0 . 0 0}$ \\
\hline & 4 & 0.00 & 0.00 & 0.00 & $\mathbf{0 . 0 0}$ & 0.00 & 0.00 & 0.00 & 0.00 & 0.00 & 0.00 & 0.00 & $\mathbf{0 . 0 0}$ & 0.00 & 0.00 & $\mathbf{0 . 0 0}$ & $\mathbf{0 . 0 0}$ & 0.00 & 0.00 & $\mathbf{0 . 0 0}$ & $\mathbf{0 . 0 0}$ \\
\hline & 5 & 0.99 & 1.00 & 1.00 & 0.80 & 0.00 & 0.79 & 1.00 & 1.00 & 0.98 & 0.02 & 0.00 & 0.58 & 1.00 & 0.96 & 0.00 & 0.00 & 0.99 & 1.00 & 0.86 & 0.01 \\
\hline & 6 & 0.86 & 0.98 & 0.98 & 0.68 & 0.01 & 0.38 & 0.97 & 0.98 & 0.85 & 0.08 & 0.00 & 0.10 & 0.85 & 0.60 & $\mathbf{0 . 0 0}$ & 0. & 0.72 & 0.88 & 0.66 & 0.05 \\
\hline & 7 & 0.75 & 0.93 & 0.93 & 0.69 & 0.12 & 0.48 & 0.92 & 0.94 & 0.83 & 0.31 & 0.01 & 0.35 & 0.86 & 0.70 & 0.04 & 0.03 & 0.75 & 0.86 & 0.72 & 0.25 \\
\hline & 8 & 0.00 & 0.00 & 0.13 & 0.18 & 0.00 & 0.00 & 0.00 & 0.10 & 0.31 & 0.01 & 0.00 & 0.00 & 0.01 & 0.15 & 0.00 & 0.00 & 0.00 & 0.06 & 0.30 & 0.02 \\
\hline & 9 & 0.00 & 0.00 & 0.00 & $\mathbf{0 . 0 0}$ & 0.00 & 0.00 & 0.00 & 0.00 & 0.00 & 0.00 & 0.00 & $\mathbf{0 . 0 0}$ & 0.00 & 0.00 & $\mathbf{0 . 0 0}$ & $\mathbf{0 . 0 0}$ & 0.00 & 0.00 & $\mathbf{0 . 0 0}$ & 0.00 \\
\hline & 10 & 0 & 0.00 & 0.00 & 0.00 & 0.00 & 0.00 & 0.00 & 0.00 & 0.00 & 0.00 & 0.00 & 0.00 & 0.00 & 0.00 & 0.00 & 0.00 & 0.00 & 0.00 & 0.00 & 0.00 \\
\hline & 11 & 0.01 & 0.00 & 0.00 & 0.00 & 0.00 & 0.00 & 0.00 & 0.00 & 0.00 & 0.00 & 0.06 & 0.00 & 0.00 & 0.00 & $\mathbf{0 . 0 0}$ & 0.00 & 0.00 & $\mathbf{0 . 0 0}$ & $\mathbf{0 . 0 0}$ & 0.00 \\
\hline \multirow{11}{*}{ 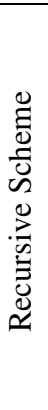 } & 1 & 05 & 0.02 & 0.12 & 0.32 & 0.36 & 0.00 & 0.01 & 0.09 & 0.32 & 0.34 & 0.01 & 0.00 & 0.00 & 0.02 & 0.14 & 0.20 & 0.01 & 0.04 & 0.25 & 0.31 \\
\hline & 2 & 0.11 & 0.02 & 0.04 & 0.01 & 0.01 & 0.00 & 0.00 & 0.01 & 0.05 & 0.09 & 0.00 & $\mathbf{0 . 0 0}$ & 0.00 & 0.00 & 0.01 & $\mathbf{0 . 0 0}$ & 0.00 & 0.00 & 0.01 & 0.04 \\
\hline & 3 & 0.04 & 0.00 & 0.00 & 0.00 & 0.00 & 0.00 & 0.00 & 0.03 & 0.00 & & 0.00 & 0.00 & 0.00 & 0.00 & 0.00 & & 0.00 & 0.00 & 0.00 & 0.00 \\
\hline & 4 & 0.01 & 0.00 & 0.00 & 0.00 & 0.00 & 0.00 & 0.00 & 0.01 & 0.00 & 0.00 & 0.00 & 0.00 & 0.00 & 0.00 & $\mathbf{0 . 0 0}$ & 0.00 & 0.00 & $\mathbf{0 . 0 0}$ & $\mathbf{0 . 0 0}$ & 0.00 \\
\hline & 5 & 0.90 & 0.99 & 0.99 & 0.91 & 0.28 & 0.66 & 0.98 & 0.99 & 0.98 & 0.69 & 0.00 & 0.71 & 0.99 & 0.94 & 0.18 & 0.01 & 0.88 & 0.98 & 0.92 & 0.53 \\
\hline & 6 & 0.86 & 0.97 & 0.98 & 0.93 & 0.43 & 0.51 & 0.95 & 0.98 & 0.97 & 0.72 & 0.00 & 0.44 & 0.93 & 0.86 & 0.10 & 0.00 & 0.81 & 0.95 & 0.91 & 0.59 \\
\hline & 7 & 0.81 & 0.95 & 0.97 & 0.90 & 0.50 & 0.52 & 0.94 & 0.97 & 0.95 & $0.7^{\circ}$ & 0.00 & 0.54 & 0.93 & 0.86 & 0.23 & 0.03 & 0.81 & 0.94 & 0.90 & 0.68 \\
\hline & 8 & 0.01 & 0.00 & 0.38 & 0.45 & 0.02 & 0.00 & 0.00 & 0.35 & 0.62 & 0.12 & 0.00 & 0.00 & 0.07 & 0.37 & 0.01 & 0.00 & 0.00 & 0.23 & 0.57 & 0.18 \\
\hline & 9 & 0.00 & 0.00 & 0.00 & $\mathbf{0 . 0 0}$ & 0.00 & 0.0 & 0.0 & 0.0 & 0.00 & 0. & 0.1 & $\mathbf{0 . 0 0}$ & 0.00 & 0.00 & 0.00 & 0.00 & 0.00 & 0.00 & 0.00 & $\mathbf{0 . 0 0}$ \\
\hline & 10 & 0.01 & 0.00 & 0.00 & 0.00 & 0.00 & 0.00 & 0.00 & 0.00 & 0.00 & 0.00 & 0.00 & 0.00 & 0.00 & 0.00 & $\mathbf{0 . 0 0}$ & 0.00 & 0.00 & $\mathbf{0 . 0 0}$ & $\mathbf{0 . 0 0}$ & 0.00 \\
\hline & 11 & 0.01 & 0.00 & 0.00 & 0.00 & 0.00 & 0.00 & 0.00 & 0.00 & 0.00 & $\mathbf{0 . 0 0}$ & $\mathbf{0 . 0 3}$ & 0.00 & 0.00 & 0.00 & 0.00 & 0.00 & 0.00 & 0.00 & 0.00 & 0.00 \\
\hline
\end{tabular}


Table 7, Forecast Breakdown Tests, Energy II and Industrial Metals I

\begin{tabular}{|c|c|c|c|c|c|c|c|c|c|c|c|c|c|c|c|c|c|c|c|c|c|}
\hline & & \multicolumn{5}{|c|}{ Natural Gas } & \multicolumn{5}{|c|}{ Gas Oil } & \multicolumn{5}{|c|}{ Aluminium } & \multicolumn{5}{|c|}{ Copper } \\
\hline & $\mathrm{BP}$ & $1 \mathrm{M}$ & $3 \mathrm{M}$ & $6 \mathrm{M}$ & $9 \mathrm{M}$ & $12 \mathrm{M}$ & $1 \mathrm{M}$ & $3 \mathrm{M}$ & $6 \mathrm{M}$ & $9 \mathrm{M}$ & $12 \mathrm{M}$ & $1 \mathrm{M}$ & $3 \mathrm{M}$ & $6 \mathrm{M}$ & $9 \mathrm{M}$ & $12 \mathrm{M}$ & $1 \mathrm{M}$ & $3 \mathrm{M}$ & $6 \mathrm{M}$ & $9 \mathrm{M}$ & $12 \mathrm{M}$ \\
\hline \multirow{11}{*}{ 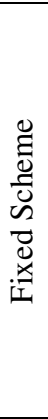 } & 1 & 0.03 & 0.01 & 0.00 & 0.00 & 0.00 & 0.01 & 0.00 & 0.00 & 0.00 & 0.00 & 0.39 & 0.89 & 0.84 & 0.74 & 0.95 & 0.10 & 0.17 & 0.01 & 0.01 & 0.02 \\
\hline & 2 & $\mathbf{0 . 0 3}$ & 0.06 & 0.13 & 0.13 & 0.32 & 0.00 & 0.00 & 0.00 & 0.00 & 0.02 & 0.96 & 1.00 & 0.99 & 1.00 & 1.00 & 0.89 & 0.93 & 0.53 & 0.47 & 0.52 \\
\hline & 3 & 0.00 & 0.00 & 0.00 & 0.04 & 0.11 & 0.00 & 0.00 & 0.00 & 0.02 & 0.00 & 0.99 & 1.00 & 1.00 & 1.00 & 1.00 & 0.84 & 0.94 & 0.82 & 0.94 & 0.99 \\
\hline & 4 & 0.00 & 0.01 & 0.05 & 0.56 & 0.89 & 0.00 & 0.00 & 0.00 & 0.00 & 0.00 & 1.00 & 1.00 & 1.00 & 1.00 & 1.00 & 0.82 & 0.82 & 0.86 & 0.93 & 0.83 \\
\hline & 5 & 0.00 & 0.07 & 0.90 & 0.97 & 0.99 & 0.85 & 0.90 & 0.93 & 0.80 & 0.27 & 1.00 & 1.00 & 1.00 & 1.00 & 1.00 & 0.96 & 0.99 & 0.99 & 1.00 & 0.99 \\
\hline & 6 & 0.00 & 0.00 & 0.61 & 0.90 & 0.96 & 0.86 & 0.95 & 0.96 & 0.92 & 0.60 & 1.00 & 1.00 & 1.00 & 1.00 & 1.00 & 0.92 & 0.95 & 0.91 & 0.57 & 0.02 \\
\hline & 7 & 0.00 & 0.04 & 0.82 & 0.97 & 0.99 & 0.92 & 0.96 & 0.97 & 0.94 & 0.82 & 1.00 & 1.00 & 1.00 & 1.00 & 1.00 & 0.91 & 0.96 & 0.95 & 0.82 & 0.27 \\
\hline & 8 & 0.00 & 0.00 & 0.47 & 0.98 & 1.00 & 0.77 & 0.14 & 0.64 & 0.75 & 0.35 & 0.95 & 0.79 & 0.97 & 0.99 & 1.00 & 0.03 & 0.00 & 0.50 & 0.58 & 0.23 \\
\hline & 9 & 0.00 & 0.00 & 0.00 & 0.00 & 0.02 & 0.00 & 0.00 & 0.00 & 0.00 & 0.00 & 0.73 & 0.00 & 0.00 & 0.00 & 0.00 & 0.02 & 0.00 & 0.00 & 0.00 & 0.00 \\
\hline & 10 & 0.00 & 0.00 & 0.03 & 0.05 & 0.12 & 0.00 & 0.00 & 0.00 & 0.00 & 0.00 & 0.43 & 0.00 & 0.00 & 0.00 & 0.00 & 0.07 & 0.00 & 0.00 & 0.00 & 0.00 \\
\hline & 11 & $\mathbf{0 . 0 0}$ & 0.09 & 0.33 & 0.49 & 0.60 & 0.00 & 0.00 & 0.00 & 0.00 & 0.00 & 0.56 & 0.00 & 0.00 & $\mathbf{0 . 0 0}$ & 0.10 & $\mathbf{0 . 0 0}$ & $\mathbf{0 . 0 0}$ & 0.00 & 0.00 & $\mathbf{0 . 0 0}$ \\
\hline \multirow{11}{*}{ 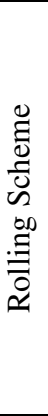 } & 1 & 0.00 & 0.00 & 0.00 & 0.00 & 0.00 & 0.00 & 0.00 & 0.00 & 0.00 & 0.03 & 0.90 & 0.94 & 0.89 & 0.66 & 0.98 & 0.30 & 0.47 & 0.32 & 0.24 & 0.33 \\
\hline & 2 & 0.00 & 0.00 & 0.18 & 0.41 & 0.62 & 0.00 & 0.00 & 0.00 & 0.00 & 0.00 & 1.00 & 1.00 & 1.00 & 1.00 & 1.00 & 0.99 & 0.61 & 0.13 & 0.12 & 0.12 \\
\hline & 3 & 0.00 & 0.00 & 0.25 & 0.79 & 0.97 & 0.00 & 0.00 & 0.00 & 0.00 & 0.00 & 1.00 & 1.00 & 0.98 & 0.96 & 0.97 & 0.52 & 0.01 & 0.00 & 0.00 & 0.00 \\
\hline & 4 & 0.00 & 0.00 & 0.08 & 0.98 & 1.00 & 0.00 & 0.00 & 0.00 & 0.00 & 0.00 & 1.00 & 1.00 & 1.00 & 1.00 & 1.00 & 0.20 & 0.00 & 0.00 & 0.00 & 0.00 \\
\hline & 5 & 0.00 & 0.00 & 0.92 & 1.00 & 1.00 & 1.00 & 1.00 & 1.00 & 0.74 & 0.00 & 1.00 & 1.00 & 1.00 & 1.00 & 1.00 & 0.98 & 1.00 & 0.89 & 0.06 & 0.00 \\
\hline & 6 & 0.00 & 0.00 & 0.49 & 0.95 & 1.00 & 0.81 & 0.90 & 0.89 & 0.59 & 0.01 & 1.00 & 1.00 & 1.00 & 1.00 & 1.00 & 0.64 & 0.39 & 0.12 & 0.00 & 0.00 \\
\hline & 7 & 0.00 & 0.00 & 0.65 & 0.95 & 0.99 & 0.84 & 0.87 & 0.86 & 0.65 & 0.11 & 1.00 & 1.00 & 1.00 & 1.00 & 0.99 & 0.69 & 0.63 & 0.36 & 0.03 & 0.00 \\
\hline & 8 & 0.00 & 0.00 & 0.29 & 0.97 & 1.00 & 0.55 & 0.00 & 0.20 & 0.30 & 0.00 & 0.83 & 0.20 & 0.86 & 0.98 & 1.00 & 0.00 & 0.00 & 0.01 & 0.01 & 0.00 \\
\hline & 9 & 0.00 & 0.00 & 0.00 & 0.01 & 0.04 & 0.00 & 0.00 & 0.00 & 0.00 & 0.00 & 0.58 & 0.00 & 0.00 & 0.00 & 0.00 & 0.00 & 0.00 & 0.00 & 0.00 & 0.00 \\
\hline & 10 & 0.00 & 0.00 & 0.03 & 0.06 & 0.15 & 0.00 & 0.00 & 0.00 & 0.00 & 0.00 & 0.38 & 0.00 & 0.00 & 0.00 & 0.00 & 0.02 & 0.00 & 0.00 & 0.00 & 0.00 \\
\hline & 11 & 0.00 & 0.06 & 0.31 & 0.47 & 0.60 & 0.00 & 0.00 & 0.00 & 0.00 & 0.00 & 0.54 & 0.00 & 0.00 & 0.00 & 0.04 & 0.00 & 0.00 & 0.00 & 0.00 & 0.00 \\
\hline \multirow{11}{*}{ 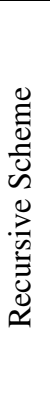 } & 1 & 0.15 & 0.00 & 0.00 & 0.00 & 0.00 & 0.01 & 0.01 & 0.02 & 0.19 & 0.28 & 0.71 & 0.79 & 0.75 & 0.61 & 0.87 & 0.42 & 0.46 & 0.37 & 0.35 & 0.42 \\
\hline & 2 & 0.00 & 0.01 & 0.10 & 0.19 & 0.29 & 0.00 & 0.00 & 0.00 & 0.03 & 0.08 & 0.99 & 1.00 & 0.98 & 0.98 & 0.99 & 0.85 & 0.67 & 0.33 & 0.33 & 0.35 \\
\hline & 3 & 0.00 & 0.00 & 0.03 & 0.21 & 0.49 & 0.00 & 0.00 & 0.00 & 0.00 & 0.00 & 1.00 & 1.00 & 0.99 & 0.98 & 0.99 & 0.70 & 0.30 & 0.02 & 0.01 & 0.00 \\
\hline & 4 & 0.00 & 0.00 & 0.02 & 0.62 & 0.98 & 0.00 & 0.00 & 0.00 & 0.00 & 0.00 & 1.00 & 1.00 & 1.00 & 1.00 & 1.00 & 0.61 & 0.09 & 0.24 & 0.21 & $\mathbf{0 . 0 3}$ \\
\hline & 5 & 0.00 & 0.00 & 0.80 & 0.99 & 1.00 & 0.95 & 0.96 & 0.97 & 0.87 & 0.26 & 1.00 & 1.00 & 1.00 & 1.00 & 1.00 & 0.96 & 0.99 & 0.98 & 0.92 & 0.26 \\
\hline & 6 & 0.00 & 0.00 & 0.54 & 0.91 & 0.98 & 0.84 & 0.93 & 0.94 & 0.87 & 0.37 & 1.00 & 1.00 & 1.00 & 1.00 & 1.00 & 0.90 & 0.91 & 0.86 & 0.45 & 0.01 \\
\hline & 7 & 0.00 & 0.01 & 0.65 & 0.94 & 0.98 & 0.86 & 0.91 & 0.93 & 0.85 & 0.48 & 1.00 & 1.00 & 1.00 & 1.00 & 1.00 & 0.88 & 0.92 & 0.87 & 0.59 & 0.07 \\
\hline & 8 & 0.00 & 0.00 & 0.26 & 0.96 & 1.00 & 0.64 & 0.02 & 0.42 & 0.55 & 0.09 & 0.94 & 0.68 & 0.96 & 0.99 & 1.00 & 0.02 & 0.00 & 0.19 & 0.23 & 0.04 \\
\hline & 9 & 0.00 & 0.00 & 0.00 & 0.00 & 0.03 & 0.00 & 0.00 & 0.00 & 0.00 & 0.00 & 0.71 & 0.00 & 0.00 & 0.00 & 0.00 & 0.02 & 0.00 & 0.00 & 0.00 & 0.00 \\
\hline & 10 & 0.00 & 0.00 & 0.02 & 0.05 & 0.12 & 0.00 & 0.00 & 0.00 & 0.00 & 0.00 & 0.44 & 0.00 & 0.00 & 0.00 & 0.00 & 0.05 & 0.00 & 0.00 & 0.00 & 0.00 \\
\hline & 11 & 0.00 & 0.06 & 0.28 & 0.44 & 0.56 & 0.00 & 0.00 & 0.00 & 0.00 & 0.00 & 0.55 & 0.00 & 0.00 & $\mathbf{0 . 0 0}$ & 0.08 & 0.00 & 0.00 & 0.00 & 0.00 & 0.00 \\
\hline
\end{tabular}


Table 8, Forecast Breakdown Tests, Industrial Metals II

\begin{tabular}{|c|c|c|c|c|c|c|c|c|c|c|c|c|c|c|c|c|c|c|c|c|c|}
\hline & & & & Lead & & & & & Nicke & & & & & Zinc & & & & & Tin & & \\
\hline & BP & $1 \mathrm{M}$ & $3 \mathrm{M}$ & $6 \mathrm{M}$ & $9 \mathrm{M}$ & $12 \mathrm{M}$ & $1 \mathrm{M}$ & $3 \mathrm{M}$ & $6 \mathrm{M}$ & $9 \mathrm{M}$ & $12 \mathrm{M}$ & $1 \mathrm{M}$ & $3 \mathrm{M}$ & $6 \mathrm{M}$ & $9 \mathrm{M}$ & $12 \mathrm{M}$ & $1 \mathrm{M}$ & $3 \mathrm{M}$ & $6 \mathrm{M}$ & $9 \mathrm{M}$ & $12 \mathrm{M}$ \\
\hline \multirow{11}{*}{ 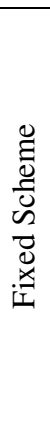 } & 1 & 0.95 & 0.96 & 0.97 & 0.96 & 0.94 & 0.08 & 0.03 & 0.03 & 0.02 & 0.05 & 0.93 & 0.12 & $\mathbf{0 . 0 0}$ & 0.00 & 0.01 & 0.84 & 0.78 & 0.28 & 0.01 & 0.05 \\
\hline & 2 & 0.96 & 0.99 & 0.99 & 0.99 & 0.99 & 0.77 & 0.30 & 0.28 & 0.60 & 0.47 & 0.99 & 0.92 & 0.05 & 0.00 & 0.00 & 0.98 & 1.00 & 0.98 & 0.77 & 0.70 \\
\hline & 3 & 0.97 & 0.95 & 0.91 & 0.97 & 0.97 & 0.05 & 0.01 & 0.00 & 0.00 & 0.00 & 1.00 & 0.98 & 0.22 & 0.01 & 0.00 & 1.00 & 1.00 & 1.00 & 1.00 & 1.00 \\
\hline & 4 & 0.87 & 0.94 & 0.89 & 0.84 & 0.37 & 0.02 & 0.46 & 0.44 & 0.44 & 0.18 & 1.00 & 1.00 & 0.99 & 0.97 & 0.91 & 0.99 & 0.98 & 0.95 & 0.78 & 0.85 \\
\hline & 5 & 1.00 & 1.00 & 1.00 & 1.00 & 0.99 & 0.87 & 0.99 & 1.00 & 1.00 & 0.99 & 0.98 & 1.00 & 1.00 & 1.00 & 1.00 & 1.00 & 1.00 & 1.00 & 1.00 & 1.00 \\
\hline & 6 & 1.00 & 1.00 & 1.00 & 1.00 & 1.00 & 0.83 & 0.96 & 0.85 & 0.82 & 0.82 & 0.94 & 0.90 & 0.69 & 0.35 & 0.10 & 1.00 & 1.00 & 1.00 & 1.00 & 1.00 \\
\hline & 7 & 0.99 & 0.97 & 0.94 & 0.87 & 0.62 & 0.76 & 0.84 & 0.65 & 0.66 & 0.49 & 0.86 & 0.80 & 0.79 & 0.65 & 0.28 & 1.00 & 1.00 & 1.00 & 0.98 & 0.95 \\
\hline & 8 & 0.03 & 0.00 & 0.32 & 0.06 & 0.04 & 0.00 & 0.00 & 0.01 & 0.02 & 0.09 & 0.16 & 0.00 & 0.02 & 0.00 & 0.00 & 0.78 & 0.49 & 0.89 & 0.93 & 0.81 \\
\hline & 9 & 0.02 & 0.00 & $\mathbf{0 . 0 0}$ & 0.00 & 0.00 & 0.00 & 0.00 & 0.00 & 0.00 & 0.00 & 0.18 & 0.00 & 0.00 & 0.00 & 0.00 & 0.83 & 0.40 & 0.10 & 0.15 & 0.48 \\
\hline & 10 & 0.00 & 0.00 & 0.00 & $\mathbf{0 . 0 0}$ & 0.00 & $\mathbf{0 . 0 0}$ & 0.00 & 0.00 & 0.00 & 0.00 & 0.01 & 0.00 & 0.00 & 0.00 & 0.00 & 0.87 & 0.42 & 0.09 & 0.12 & 0.02 \\
\hline & 11 & $\mathbf{0 . 0 0}$ & 0.00 & $\mathbf{0 . 0 0}$ & 0.00 & $\mathbf{0 . 0 0}$ & $\mathbf{0 . 0 0}$ & 0.00 & $\mathbf{0 . 0 0}$ & $\mathbf{0 . 0 0}$ & $\mathbf{0 . 0 0}$ & 0.02 & $\mathbf{0 . 0 0}$ & $\mathbf{0 . 0 0}$ & 0.00 & 0.00 & 0.67 & 0.11 & 0.00 & $\mathbf{0 . 0 0}$ & $\mathbf{0 . 0 0}$ \\
\hline \multirow{11}{*}{ 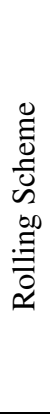 } & 1 & 0.99 & 0.91 & 0.78 & 0.56 & 0.64 & 0.38 & 0.00 & 0.06 & 0.19 & 0.41 & 0.98 & 0.59 & 0.15 & 0.02 & 0.02 & 0.97 & 0.98 & 0.71 & 0.04 & 0.06 \\
\hline & 2 & 0.96 & 0.88 & 0.17 & 0.10 & 0.15 & 0.09 & 0.02 & 0.01 & $\mathbf{0 . 0 3}$ & 0.01 & 1.00 & 0.97 & 0.58 & 0.45 & 0.36 & 1.00 & 1.00 & 0.95 & 0.26 & 0.16 \\
\hline & 3 & 0.45 & 0.06 & 0.00 & 0.00 & 0.00 & 0.00 & 0.00 & 0.00 & 0.00 & 0.00 & 0.96 & 0.10 & 0.00 & 0.00 & 0.00 & 1.00 & 1.00 & 0.95 & 0.67 & 0.77 \\
\hline & 4 & 0.04 & 0.00 & 0.01 & 0.00 & 0.00 & 0.00 & 0.00 & 0.00 & 0.00 & 0.00 & 0.37 & 0.00 & 0.00 & 0.00 & 0.00 & 0.99 & 0.98 & 0.91 & 0.52 & 0.38 \\
\hline & 5 & 0.33 & 0.11 & 0.27 & 0.10 & 0.00 & 0.14 & 0.24 & 0.03 & 0.00 & 0.00 & 0.53 & 0.00 & 0.00 & 0.00 & 0.00 & 1.00 & 1.00 & 1.00 & 0.97 & 0.29 \\
\hline & 6 & 0.83 & 0.53 & 0.37 & 0.29 & 0.07 & 0.05 & 0.09 & 0.00 & 0.00 & 0.00 & 0.21 & 0.00 & 0.00 & 0.00 & 0.00 & 0.99 & 0.99 & 0.93 & 0.66 & 0.46 \\
\hline & 7 & 0.59 & 0.29 & 0.04 & 0.02 & 0.00 & 0.19 & 0.12 & 0.00 & $\mathbf{0 . 0 0}$ & $\mathbf{0 . 0 0}$ & 0.29 & 0.01 & $\mathbf{0 . 0 0}$ & 0.00 & 0.00 & 0.98 & 0.99 & 0.92 & 0.57 & 0.14 \\
\hline & 8 & $\mathbf{0 . 0 0}$ & 0.00 & $\mathbf{0 . 0 0}$ & 0.00 & $\mathbf{0 . 0 0}$ & $\mathbf{0 . 0 0}$ & 0.00 & $\mathbf{0 . 0 0}$ & $\mathbf{0 . 0 0}$ & $\mathbf{0 . 0 0}$ & 0.00 & 0.00 & 0.00 & 0.00 & 0.00 & 0.55 & 0.08 & 0.39 & 0.49 & 0.14 \\
\hline & 9 & 0.00 & 0.00 & 0.00 & 0.00 & 0.00 & 0.00 & 0.00 & 0.00 & 0.00 & 0.00 & 0.01 & 0.00 & 0.00 & 0.00 & 0.00 & 0.72 & 0.11 & 0.00 & 0.01 & 0.04 \\
\hline & 10 & 0.00 & 0.00 & 0.00 & 0.00 & 0.00 & 0.00 & 0.00 & 0.00 & 0.00 & 0.00 & 0.00 & 0.00 & 0.00 & 0.00 & 0.00 & 0.81 & 0.20 & 0.01 & 0.02 & 0.00 \\
\hline & 11 & $\mathbf{0 . 0 0}$ & 0.00 & $\mathbf{0 . 0 0}$ & 0.00 & $\mathbf{0 . 0 0}$ & $\mathbf{0 . 0 0}$ & $\mathbf{0 . 0 0}$ & $\mathbf{0 . 0 0}$ & $\mathbf{0 . 0 0}$ & $\mathbf{0 . 0 0}$ & $\mathbf{0 . 0 0}$ & $\mathbf{0 . 0 0}$ & $\mathbf{0 . 0 0}$ & $\mathbf{0 . 0 0}$ & $\mathbf{0 . 0 0}$ & 0.63 & 0.08 & 0.00 & $\mathbf{0 . 0 0}$ & $\mathbf{0 . 0 0}$ \\
\hline \multirow{11}{*}{ 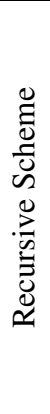 } & 1 & 0.81 & 0.72 & 0.63 & 0.53 & 0.57 & 0.31 & 0.14 & 0.26 & 0.35 & 0.41 & 0.83 & 0.49 & 0.22 & 0.11 & 0.14 & 0.88 & 0.83 & 0.58 & 0.18 & 0.23 \\
\hline & 2 & 0.88 & 0.86 & 0.56 & 0.45 & 0.49 & 0.35 & 0.18 & 0.15 & 0.28 & 0.18 & 0.98 & 0.82 & 0.40 & 0.30 & 0.26 & 0.99 & 1.00 & 0.88 & 0.48 & 0.38 \\
\hline & 3 & 0.82 & 0.55 & 0.08 & $\mathbf{0 . 0 3}$ & 0.01 & 0.00 & 0.02 & 0.00 & 0.01 & 0.00 & 0.98 & 0.55 & 0.03 & 0.03 & 0.02 & 1.00 & 1.00 & 0.98 & 0.91 & 0.96 \\
\hline & 4 & 0.64 & 0.48 & 0.71 & 0.59 & 0.03 & 0.01 & 0.10 & 0.02 & 0.00 & 0.00 & 0.96 & 0.26 & 0.11 & 0.05 & 0.00 & 0.99 & 0.99 & 0.98 & 0.90 & 0.93 \\
\hline & 5 & 0.96 & 0.94 & 0.98 & 0.94 & 0.66 & 0.68 & 0.88 & 0.84 & 0.80 & 0.64 & 0.95 & 0.79 & 0.69 & 0.37 & 0.13 & 1.00 & 1.00 & 1.00 & 1.00 & 0.95 \\
\hline & 6 & 1.00 & 0.99 & 1.00 & 0.99 & 0.97 & 0.53 & 0.83 & 0.40 & 0.19 & 0.06 & 0.90 & 0.73 & 0.45 & 0.14 & 0.01 & 1.00 & 1.00 & 1.00 & 0.99 & 1.00 \\
\hline & 7 & 0.96 & 0.91 & 0.75 & 0.62 & 0.23 & 0.54 & 0.64 & 0.31 & 0.31 & 0.17 & 0.83 & 0.56 & 0.41 & 0.22 & $\mathbf{0 . 0 3}$ & 1.00 & 1.00 & 0.99 & 0.95 & 0.81 \\
\hline & 8 & 0.01 & 0.00 & 0.08 & 0.00 & $\mathbf{0 . 0 0}$ & $\mathbf{0 . 0 0}$ & 0.00 & $\mathbf{0 . 0 0}$ & $\mathbf{0 . 0 0}$ & 0.01 & 0.10 & 0.00 & 0.00 & 0.00 & 0.00 & 0.80 & 0.45 & 0.79 & 0.83 & 0.61 \\
\hline & 9 & 0.01 & 0.00 & $\mathbf{0 . 0 0}$ & $\mathbf{0 . 0 0}$ & $\mathbf{0 . 0 0}$ & $\mathbf{0 . 0 0}$ & 0.00 & $\mathbf{0 . 0 0}$ & $\mathbf{0 . 0 0}$ & $\mathbf{0 . 0 0}$ & 0.12 & $\mathbf{0 . 0 0}$ & $\mathbf{0 . 0 0}$ & 0.00 & 0.00 & 0.84 & 0.38 & 0.07 & $\mathbf{0 . 0 8}$ & 0.29 \\
\hline & 10 & 0.00 & 0.00 & $\mathbf{0 . 0 0}$ & 0.00 & 0.00 & 0.00 & 0.00 & 0.00 & 0.00 & 0.00 & 0.01 & 0.00 & 0.00 & 0.00 & 0.00 & 0.86 & 0.38 & 0.06 & 0.06 & 0.01 \\
\hline & 11 & $\mathbf{0 . 0 0}$ & 0.00 & 0.00 & 0.00 & 0.00 & $\mathbf{0 . 0 0}$ & 0.00 & 0.00 & $\mathbf{0 . 0 0}$ & $\mathbf{0 . 0 0}$ & 0.01 & 0.00 & 0.00 & 0.00 & 0.00 & 0.66 & 0.11 & 0.00 & 0.00 & 0.00 \\
\hline
\end{tabular}


Table 9, Forecast Breakdown Tests, Precious Metals

\begin{tabular}{|c|c|c|c|c|c|c|c|c|c|c|c|c|c|c|c|}
\hline & & \multicolumn{5}{|c|}{ Gold } & \multicolumn{5}{|c|}{ Silver } & \multicolumn{2}{|c|}{ Platinum } & \multicolumn{2}{|c|}{ Palladium } \\
\hline & $\mathrm{BP}$ & $1 \mathrm{M}$ & $3 \mathrm{M}$ & $6 \mathrm{M}$ & $9 \mathrm{M}$ & $12 \mathrm{M}$ & $1 \mathrm{M}$ & $3 \mathrm{M}$ & $6 \mathrm{M}$ & $9 \mathrm{M}$ & $12 \mathrm{M}$ & $1 \mathrm{M}$ & $3 \mathrm{M}$ & $1 \mathrm{M}$ & $3 \mathrm{M}$ \\
\hline \multirow{11}{*}{ 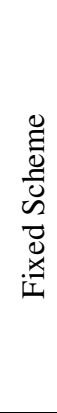 } & 1 & 0.92 & 0.94 & 0.93 & 0.80 & 0.36 & 0.95 & 0.98 & 0.95 & 0.81 & 0.83 & 0.94 & 0.02 & 0.01 & 0.01 \\
\hline & 2 & 0.99 & 0.97 & 0.98 & 0.96 & 0.96 & 0.98 & 1.00 & 1.00 & 0.99 & 0.98 & 0.82 & 0.00 & 0.00 & 0.00 \\
\hline & 3 & 0.99 & 0.97 & 0.99 & 1.00 & 1.00 & 1.00 & 1.00 & 1.00 & 1.00 & 1.00 & 0.79 & 0.00 & 0.00 & 0.00 \\
\hline & 4 & 0.99 & 0.99 & 1.00 & 1.00 & 1.00 & 0.99 & 1.00 & 1.00 & 1.00 & 1.00 & 0.83 & $\mathbf{0 . 0 0}$ & $\mathbf{0 . 0 0}$ & 0.00 \\
\hline & 5 & 1.00 & 1.00 & 1.00 & 1.00 & 1.00 & 1.00 & 1.00 & 1.00 & 1.00 & 1.00 & 0.96 & 0.94 & 0.16 & 0.52 \\
\hline & 6 & 1.00 & 1.00 & 1.00 & 1.00 & 1.00 & 1.00 & 1.00 & 1.00 & 1.00 & 1.00 & 0.98 & 0.97 & 0.43 & 0.53 \\
\hline & 7 & 1.00 & 1.00 & 1.00 & 1.00 & 1.00 & 1.00 & 1.00 & 1.00 & 1.00 & 1.00 & 0.98 & 0.97 & 0.53 & 0.63 \\
\hline & 8 & 0.88 & 0.94 & 0.87 & 0.97 & 0.99 & 0.98 & 0.98 & 1.00 & 1.00 & 1.00 & 0.95 & 0.94 & 0.25 & 0.77 \\
\hline & 9 & 0.76 & 0.67 & 0.81 & 0.97 & 1.00 & 0.96 & 0.97 & 0.99 & 0.99 & 1.00 & 0.04 & 0.00 & 0.00 & 0.00 \\
\hline & 10 & 0.92 & 0.71 & 0.73 & 0.75 & 0.87 & 0.98 & 0.91 & 0.98 & 0.98 & 0.99 & 0.25 & 0.00 & 0.00 & 0.00 \\
\hline & 11 & 0.49 & 0.72 & 0.53 & 0.28 & 0.02 & 0.26 & 0.70 & 0.25 & 0.15 & 0.00 & 0.57 & 0.00 & 0.01 & $\mathbf{0 . 0 0}$ \\
\hline \multirow{11}{*}{ 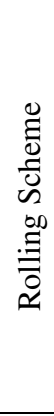 } & 1 & 0.94 & 0.95 & 0.95 & 0.87 & 0.76 & 0.99 & 1.00 & 0.99 & 0.92 & 0.94 & 0.29 & $\mathbf{0 . 0 0}$ & 0.00 & 0.00 \\
\hline & 2 & 1.00 & 0.96 & 0.99 & 0.98 & 1.00 & 1.00 & 1.00 & 1.00 & 1.00 & 1.00 & 1.00 & $\mathbf{0 . 0 0}$ & $\mathbf{0 . 0 0}$ & 0.00 \\
\hline & 3 & 1.00 & 0.98 & 0.99 & 1.00 & 1.00 & 1.00 & 1.00 & 1.00 & 1.00 & 1.00 & 0.99 & 0.01 & 0.00 & 0.00 \\
\hline & 4 & 1.00 & 0.99 & 0.96 & 1.00 & 1.00 & 1.00 & 1.00 & 1.00 & 1.00 & 1.00 & 0.99 & 0.23 & 0.00 & 0.00 \\
\hline & 5 & 1.00 & 0.99 & 0.80 & 0.97 & 1.00 & 1.00 & 1.00 & 1.00 & 1.00 & 1.00 & 1.00 & 1.00 & 0.42 & 1.00 \\
\hline & 6 & 1.00 & 1.00 & 0.96 & 0.98 & 0.99 & 1.00 & 1.00 & 1.00 & 1.00 & 1.00 & 1.00 & 1.00 & 0.83 & 0.92 \\
\hline & 7 & 1.00 & 0.97 & 0.94 & 0.98 & 0.99 & 1.00 & 1.00 & 1.00 & 1.00 & 1.00 & 0.99 & 0.98 & 0.64 & 0.72 \\
\hline & 8 & 0.71 & 0.85 & 0.64 & 0.83 & 0.96 & 0.95 & 0.93 & 0.97 & 0.99 & 1.00 & 0.95 & 0.94 & 0.21 & 0.81 \\
\hline & 9 & 0.64 & 0.58 & 0.67 & 0.90 & 0.98 & 0.93 & 0.93 & 0.97 & 0.98 & 0.99 & 0.01 & 0.00 & 0.00 & 0.00 \\
\hline & 10 & 0.87 & 0.68 & 0.67 & 0.66 & 0.79 & 0.96 & 0.87 & 0.97 & 0.96 & 0.99 & 0.17 & $\mathbf{0 . 0 0}$ & 0.00 & 0.00 \\
\hline & 11 & 0.46 & 0.71 & 0.53 & 0.29 & 0.01 & 0.20 & 0.67 & 0.23 & 0.13 & 0.00 & 0.50 & $\mathbf{0 . 0 0}$ & 0.01 & $\mathbf{0 . 0 0}$ \\
\hline \multirow{11}{*}{ 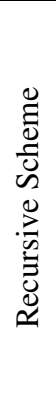 } & 1 & 0.91 & 0.94 & 0.93 & 0.80 & 0.48 & 0.93 & 0.98 & 0.96 & 0.82 & 0.77 & 0.60 & 0.02 & 0.00 & 0.00 \\
\hline & 2 & 1.00 & 0.96 & 0.98 & 0.96 & 0.97 & 0.99 & 1.00 & 1.00 & 0.99 & 0.99 & 0.93 & 0.00 & 0.00 & 0.00 \\
\hline & 3 & 1.00 & 0.98 & 0.99 & 1.00 & 1.00 & 1.00 & 1.00 & 1.00 & 1.00 & 1.00 & 0.89 & $\mathbf{0 . 0 0}$ & 0.00 & 0.00 \\
\hline & 4 & 1.00 & 0.99 & 0.99 & 1.00 & 1.00 & 1.00 & 1.00 & 1.00 & 1.00 & 1.00 & 0.91 & 0.00 & 0.00 & 0.00 \\
\hline & 5 & 1.00 & 1.00 & 0.98 & 1.00 & 1.00 & 1.00 & 1.00 & 1.00 & 1.00 & 1.00 & 1.00 & 0.99 & 0.17 & 0.74 \\
\hline & 6 & 1.00 & 1.00 & 1.00 & 1.00 & 1.00 & 1.00 & 1.00 & 1.00 & 1.00 & 1.00 & 1.00 & 0.98 & 0.42 & 0.58 \\
\hline & 7 & 1.00 & 0.99 & 0.99 & 1.00 & 1.00 & 1.00 & 1.00 & 1.00 & 1.00 & 1.00 & 0.99 & 0.96 & 0.34 & 0.48 \\
\hline & 8 & 0.89 & 0.94 & 0.86 & 0.96 & 0.99 & 0.98 & 0.98 & 1.00 & 1.00 & 1.00 & 0.95 & 0.92 & 0.11 & 0.62 \\
\hline & 9 & 0.78 & 0.71 & 0.80 & 0.95 & 0.99 & 0.96 & 0.97 & 0.99 & 0.99 & 1.00 & 0.05 & $\mathbf{0 . 0 0}$ & 0.00 & 0.00 \\
\hline & 10 & 0.91 & 0.73 & 0.74 & 0.73 & 0.84 & 0.97 & 0.92 & 0.98 & 0.97 & 0.99 & 0.26 & 0.00 & 0.00 & 0.00 \\
\hline & 11 & 0.50 & 0.73 & 0.56 & 0.31 & 0.02 & 0.26 & 0.72 & 0.29 & 0.17 & 0.00 & 0.55 & 0.00 & 0.00 & 0.00 \\
\hline
\end{tabular}

Note to Tables 4-9: The table reports p-values for the Giacomini and Rossi (2009) test. Bold numbers denote cases that reject the null hypothesis of no forecast breakdown. Symbols $1 \mathrm{M}, 2 \mathrm{M}$ etc denote months to maturity, BP denotes breaking point 
often detected. As a result, this evidence suggests the formation of three rough four-year periods, during which the futures market disconnects from the spot market periodically. This evidence is largely consistent for a large number of commodities across contract maturities but we also observe a number of distinctive exceptions. In particular, we observe strong stability of the market price forecasting performance for specific maturities of some metals and agricultural and livestock contracts. This concerns Gold and Silver for all maturities except 12-month for braking point 11 (that is June 2012), Tin and Aluminium for 1-month contracts and weaker for Platinum 1-month contract, Oats for all maturities and weaker evidence for Milk and Feeder Cattle 1-month and Lean Hogs 3-month contracts. On the other side, we observe strong instability of the market price forecasting performance for specific maturities of some energy and agricultural contracts. This concerns Coffee and Cocoa 1month and Live Cattle 33-month contracts with weaker evidence for Rice and Live Cattle 1month contracts, as well as, Gasoline 1-month and Natural Gas 1- and 3-month and weaker for the Heating Oil 1-month contract.

\section{Periodic Joint Preference Asymmetries}

In response to our evidence suggesting the presence of market pricing forecast breakdowns, we re-estimate market loss preferences in three sequential sub-periods. This is motivated by our evidence in Section 5 suggesting, on average, the presence of forecast breakdowns during the first and the last four years in our sample, interrupted by a period without breaks. Each period covers roughly 50 observations of our initial sample, thus corresponding to 20012004, 2005- 2008, 2009-mid 2013.

An overview of our empirical results in Tables 10-14 reveals the presence of more extensive asymmetric preferences as compared to our full sample results in Tables 2-3. Preference asymmetries are now observed also for shorter maturities which often start from 1-month. Periodic estimation of market loss preferences also reveals a rich variety of preference term structure shapes. For $p=2$, we observe twelve different shapes of joint preferences: flat (fully symmetric, fully optimistic, fully pessimistic) where preferences remain qualitatively the same for all maturities, sloping (symmetric - optimistic, symmetric - pessimistic, optimistic symmetric, pessimistic - symmetric) where preferences appear symmetric for short (long) maturities and asymmetric for longer (shorter) maturities and oscillating (symmetric pessimistic - symmetric, symmetric -pessimistic - optimistic, symmetric - pessimistic symmetric - optimistic, optimistic - symmetric - optimistic, optimistic - symmetric - 
pessimistic) where preference regimes tend to rotate across maturities. The shapes of preference term structures admit the same interpretation in relation to the shape of futures curves versus the spot prices in the future and Graph 2 presents representative examples for five commodities. Our evidence suggests that for agriculture across the three periods, we observe the presence of generally pessimistic preferences for Wheat, Oats and Rice, optimistic preferences for Sugar and Soybeans, a flight from general pessimism to optimism for Corn and Cotton and a flight from general optimism to pessimism for Coffee, Cocoa, Milk and Soybean Oil. We also observe a flight from general optimism to pessimism for livestock commodities. For the commodities in the energy sector we observe an evolution of preferences from general optimism (symmetric-optimistic) to oscillating preferences in the period 2005-2008 (symmetric - pessimistic - symmetric - optimistic) and then back to general optimism (symmetric-optimistic) in the last period 2009-2013, noting the exception of Natural Gas which evolved into generally pessimistic preferences. For industrial metals, we observe generally optimistic preferences across the three sub-periods (symmetric-optimistic), except of Aluminium and Zinc which evolved to oscillating preferences (symmetric pessimistic - symmetric - optimistic) in the second and third sub-period respectively. Finally, for precious metals we observe general optimistic preferences (symmetric-optimistic) across sub-periods, except of Palladium which evolved from symmetric-pessimistic to pure symmetric preferences.

Overall, our periodic evidence suggests the presence of generally optimistic preferences for most assets in sub-period 2001-2004, which evolved into oscillating preferences in sub-period 2005-2008 of the general form symmetric - pessimistic - symmetric - optimistic which involve pessimism for medium maturities and finally back to general optimistic preferences in sub-period 2009-2013 but at a smaller scale. Moreover, the preference term structure in the first and the third sub-periods exhibits sloping shape, while in the second sub-period which contains the market turmoil the term structure is oscillating. Our evidence for $p=2$ reveals a much richer set of preference term structure shapes as compared to those estimated for $p=1$ in forty out of the total ninety cases estimated in Tables 10-14 over the three sub-periods. Moreover, our estimate for the $J$ statistic generally cannot reject the null hypothesis of forecast rationality in the majority of cases for $1 \%$ level, although there are a small number of rejections for 5\% level as compared to our full sample analysis. 
Table 10. Periodic Loss Function Estimation, Agricultural Commodities, 2001-2004, 2005-2008, 2009-2013

\begin{tabular}{|c|c|c|c|c|c|c|c|c|c|c|c|c|c|c|c|c|c|c|c|c|c|}
\hline & \multicolumn{3}{|c|}{ Wheat } & \multicolumn{3}{|c|}{ Corn } & \multicolumn{3}{|c|}{ Soybeans } & \multicolumn{3}{|c|}{ Cotton } & \multicolumn{3}{|c|}{ Sugar } & \multicolumn{3}{|c|}{ Coffee } & \multicolumn{3}{|c|}{ Cocoa } \\
\hline & 1 & 2 & 3 & 1 & 2 & 3 & 1 & 2 & 3 & 1 & 2 & 3 & 1 & 2 & 3 & 1 & 2 & 3 & 1 & 2 & 3 \\
\hline \multicolumn{22}{|c|}{ Quadratic Specification $(p=2)$} \\
\hline \multirow[t]{2}{*}{$\tau_{1}$} & 0.14 & 0.4 & 0.2 & 0.15 & 0.16 & 0.02 & -0.08 & 0.19 & -0.07 & -0.11 & -0.13 & -0.05 & -0.34 & -0.58 & -0.17 & -0.61 & -0.68 & 0.017 & -0.18 & -0.56 & -0.49 \\
\hline & 0.33 & 0.26 & 0.33 & 0.16 & 0.2 & 0.36 & 0.24 & 0.29 & 0.32 & 0.31 & 0.31 & 0.28 & 0.21 & 0.3 & 0.29 & 0.31 & 0.28 & 0.35 & 0.35 & 0.44 & 0.56 \\
\hline \multirow[t]{2}{*}{$\tau_{2}$} & 0.51 & 0.56 & 0.5 & 0.29 & 0.42 & -0.03 & -0.31 & 0.44 & -0.3 & 0.24 & 0.4 & -0.33 & -0.63 & -0.54 & -0.55 & -0.09 & -0.39 & 0.36 & -0.48 & -0.41 & -0.06 \\
\hline & 0.28 & 0.28 & 0.24 & 0.17 & 0.21 & 0.39 & 0.29 & 0.33 & 0.33 & 0.2 & 0.24 & 0.29 & 0.14 & 0.21 & 0.18 & 0.32 & 0.44 & 0.43 & 0.39 & 0.44 & 0.78 \\
\hline \multirow[t]{2}{*}{$\tau_{3}$} & 0.81 & 0.7 & 0.83 & 0.59 & 0.65 & -0.57 & -0.6 & -0.01 & -0.57 & 0.58 & 0.63 & -0.58 & -0.69 & -0.54 & -0.82 & 0.75 & 0.063 & 0.86 & -0.81 & -0.56 & 0.47 \\
\hline & 0.18 & 0.19 & 0.14 & 0.1 & 0.13 & 0.28 & 0.17 & 0.36 & 0.26 & 0.13 & 0.13 & 0.16 & 0.13 & 0.26 & 0.16 & 0.2 & 0.52 & 0.31 & 0.26 & 0.4 & 0.72 \\
\hline \multirow[t]{2}{*}{$\tau_{4}$} & - & - & - & 0.71 & 0.54 & -0.68 & -0.71 & -0.48 & -0.75 & 0.73 & 0.64 & -0.59 & - & - & - & - & - & - & - & - & - \\
\hline & & & & 0.13 & 0.18 & 0.32 & 0.21 & 0.33 & 0.3 & 0.11 & 0.12 & 0.24 & & & & & & & & & \\
\hline$\tau_{5}$ & - & - & - & - & - & - & - & - & - & - & - & - & - & - & - & - & - & - & - & - & - \\
\hline$J$ & 20 & 16 & 19 & 25 & 28 & 28 & 27 & 28 & 33 & 32 & 21 & 22 & 27 & 23 & 36 & 24 & 25 & 23 & 26 & 22 & 27 \\
\hline$\|\boldsymbol{\tau}\|_{2}$ & 0.97 & 0.98 & 0.99 & 0.98 & 0.96 & 0.89 & 0.99 & 0.68 & 0.99 & 0.97 & 0.99 & 0.9 & 1 & 0.96 & 1 & 0.97 & 0.79 & 0.93 & 0.96 & 0.89 & 0.68 \\
\hline \multicolumn{22}{|c|}{ Linear Specification $(p=1)$} \\
\hline \multirow[t]{2}{*}{$\tau_{1}$} & 0.34 & 0.73 & 0.49 & 1.1 & 0.64 & -0.07 & -0.32 & -0.14 & -0.31 & 0.26 & 0.042 & -0.3 & -0.93 & -0.86 & -0.84 & -0.89 & -0.79 & 0.36 & -0.62 & -0.62 & -0.5 \\
\hline & 0.92 & 0.71 & 0.83 & 0.28 & 0.69 & 0.86 & 0.8 & 0.77 & 0.79 & 0.81 & 0.83 & 0.77 & 0.48 & 0.56 & 0.6 & 0.44 & 0.51 & 0.84 & 0.84 & 0.71 & 0.87 \\
\hline \multirow[t]{2}{*}{$\tau_{2}$} & 0.75 & 0.9 & 0.83 & 1 & 0.81 & -0.34 & -0.82 & -0.33 & -0.69 & 0.87 & 0.9 & -0.48 & -0.99 & -0.89 & -0.96 & 0.3 & -0.76 & 0.76 & -0.5 & -0.75 & -0.49 \\
\hline & 0.7 & 0.37 & 0.56 & 001 & 0.4 & 0.64 & 0.43 & 0.85 & 0.6 & 0.46 & 0.43 & 0.76 & 0.14 & 0.44 & 0.41 & 0.84 & 0.56 & 0.67 & 0.69 & 0.58 & 0.87 \\
\hline \multirow[t]{2}{*}{$\tau_{3}$} & 0.96 & 0.86 & 0.92 & 1 & 0.83 & -0.77 & -0.91 & -0.59 & -0.68 & 0.86 & 1 & -0.84 & -1 & -0.86 & -0.99 & 0.87 & -0.74 & 0.84 & -0.16 & -0.83 & -0.36 \\
\hline & 0.37 & 0.48 & 0.39 & 0.01 & 0.35 & 0.51 & 0.28 & 0.53 & 0.51 & 0.46 & 0.26 & 0.39 & 0.033 & 0.47 & 0.27 & 0.41 & 0.66 & 0.57 & 0.89 & 0.57 & 0.9 \\
\hline \multirow[t]{2}{*}{$\tau_{4}$} & - & - & - & 1 & 0.83 & -0.87 & -0.95 & -0.69 & -0.71 & 0.87 & 0.99 & -0.73 & - & - & - & - & - & - & - & - & - \\
\hline & & & & 0.01 & 0.35 & 0.44 & 0.32 & 0.59 & 0.64 & 0.44 & 0.058 & 0.54 & & & & & & & & & \\
\hline$\tau_{5}$ & - & - & - & - & - & - & - & - & - & - & - & - & - & - & - & - & - & - & - & - & - \\
\hline$J$ & 20 & 13 & 13 & 20 & 39 & 33 & 27 & 28 & 28 & 20 & 25 & 30 & 14 & 17 & 33 & 23 & 26 & 25 & 31 & 20 & 32 \\
\hline$\|\boldsymbol{\tau}\|_{\infty}$ & 0.96 & 0.90 & 0.92 & 1.00 & 0.83 & 0.87 & 0.95 & 0.69 & 0.71 & 0.87 & 0.99 & 0.84 & 0.99 & 0.89 & 0.99 & 0.89 & 0.79 & 0.84 & 0.00 & 0.83 & 0.00 \\
\hline
\end{tabular}

Note: The table reports Komunjer and Owyang (2012) GMM estimation results for multivariate loss functions using $d=N+1$ instruments. $\boldsymbol{\tau}_{\mathrm{j}}, \mathrm{j}=1, \ldots, 5$ denotes the loss function parameter corresponding to futures contract maturity j. Bold numbers denote statistical significance in at least $10 \%$ level. The numbers below the estimated parameters are standard errors. The second row denotes estimation periods, (1) 2001-2004, (2) 2005-2008, (3) 2009-2013. J statistic is $X^{2}$ distributed with N(D-1) degrees of freedom. The $X^{2}$ critical values for 9 , 16 and 25 degrees of freedom at $5 \%(1 \%)$ level are $16.92(21.67), 26.30(32)$ and $37.20(44)$ respectively. 
Table 11. Periodic Loss Function Estimation, Agricultural Commodities II and Livestock, 2001-2004, 2005-2008, 2009-2013

\begin{tabular}{|c|c|c|c|c|c|c|c|c|c|c|c|c|c|c|c|c|c|c|c|c|c|}
\hline & \multicolumn{3}{|c|}{ Milk Class III } & \multicolumn{3}{|c|}{ Soybean Oil } & \multicolumn{3}{|c|}{ Oats } & \multicolumn{3}{|c|}{ Rough Rice } & \multicolumn{3}{|c|}{ Feeder Cattle } & \multicolumn{3}{|c|}{ Live Cattle } & \multicolumn{3}{|c|}{ Lean Hogs } \\
\hline & 1 & 2 & 3 & 1 & 2 & 3 & 1 & 2 & 3 & 1 & 2 & 3 & 1 & 2 & 3 & 1 & 2 & 3 & 1 & 2 & 3 \\
\hline \multicolumn{22}{|c|}{ Quadratic Specification $(p=2)$} \\
\hline \multirow[t]{2}{*}{$\tau_{1}$} & -0.01 & 0.08 & -0.03 & -0.12 & 0.06 & 0.27 & 0.71 & 0.71 & 0.70 & -0.23 & -0.56 & -0.2 & -0.17 & 0.09 & 0.25 & -0.09 & 0.22 & -0.03 & -0.64 & 0.4 & 0.43 \\
\hline & 0.02 & 0.07 & 0.13 & 0.18 & 0.09 & 0.15 & 0.01 & 0.01 & 0.01 & 0.41 & 0.53 & 0.55 & 0.26 & 0.31 & 0.41 & 0.48 & 0.52 & 0.4 & 0.23 & 0.48 & 0.4 \\
\hline \multirow[t]{2}{*}{$\tau_{2}$} & -0.21 & 0.16 & -0.22 & -0.27 & 0.18 & $\mathbf{0 . 3 8}$ & 0.70 & 0.71 & 0.71 & 0.25 & -0.42 & 0.37 & -0.51 & -0.07 & 0.45 & -0.58 & 0.65 & 0.36 & -0.57 & 0.7 & 0.63 \\
\hline & 0.21 & 0.18 & 0.21 & 0.22 & 0.1 & 0.18 & 0.01 & 0.01 & 0.01 & 0.45 & 0.43 & 0.47 & 0.29 & 0.53 & 0.43 & 0.35 & 0.6 & 0.43 & 0.17 & 0.3 & 0.23 \\
\hline \multirow[t]{2}{*}{$\tau_{3}$} & -0.26 & -0.1 & -0.27 & -0.48 & 0.14 & 0.54 & - & - & - & 0.9 & -0.3 & 0.77 & -0.77 & -0.95 & 0.054 & -0.7 & -0.02 & 0.83 & -0.48 & -0.19 & 0.59 \\
\hline & 0.32 & 0.18 & 0.38 & 0.17 & 0.1 & 0.14 & & & & 0.2 & 0.55 & 0.34 & 0.22 & 0.14 & 0.73 & 0.32 & 0.7 & 0.32 & 0.28 & 0.53 & 0.26 \\
\hline \multirow[t]{2}{*}{$\tau_{4}$} & -0.18 & -0.44 & -0.13 & -0.57 & -0.29 & 0.28 & - & - & - & - & - & - & - & - & - & - & - & - & - & - & - \\
\hline & 0.41 & 0.18 & 0.35 & 0.15 & 0.08 & 0.19 & & & & & & & & & & & & & & & \\
\hline \multirow[t]{2}{*}{$\tau_{5}$} & -0.22 & -0.61 & -0.18 & -0.59 & -0.68 & 0.15 & - & - & - & - & - & - & - & - & - & - & - & - & - & - & - \\
\hline & 0.38 & 0.2 & 0.34 & 0.14 & 0.09 & 0.35 & & & & & & & & & & & & & & & \\
\hline$J$ & 38 & 32 & 34 & 32 & 38 & 37 & 43 & 39 & 14 & 19 & 17 & 17 & 20 & 24 & 27 & 26 & 22 & 22 & 19 & 25 & 25 \\
\hline$\|\boldsymbol{\tau}\|_{2}$ & 0.43 & 0.79 & 0.42 & 1 & 0.78 & 0.78 & 1.00 & 1.00 & 1.00 & 0.97 & 0.76 & 0.88 & 0.94 & 0.96 & 0.52 & 0.91 & 0.68 & 0.9 & 0.98 & 0.83 & 0.96 \\
\hline \multicolumn{22}{|c|}{ Linear Specification $(p=1)$} \\
\hline \multirow[t]{2}{*}{$\tau_{1}$} & 0.09 & 0.13 & 0.39 & -0.59 & -0.55 & 1 & - & - & - & -0.56 & -0.94 & -0.18 & -0.6 & 0.1 & 0.16 & -0.21 & 0.1 & -0.23 & -0.92 & 0.41 & 0.19 \\
\hline & 0.69 & 0.61 & 0.65 & 0.31 & 0.4 & 0.24 & & & & 0.82 & 0.45 & 0.94 & 0.78 & 0.94 & 0.9 & 0.92 & 0.97 & 0.94 & 0.35 & 0.69 & 0.77 \\
\hline \multirow[t]{2}{*}{$\tau_{2}$} & -0.64 & -0.08 & -0.25 & -0.7 & -0.46 & 1 & - & - & - & 0.32 & -0.73 & 0.37 & -0.72 & -0.8 & 0.3 & -0.73 & 0.38 & 0.61 & -0.92 & 0.74 & 0.81 \\
\hline & 0.5 & 0.59 & 0.8 & 0.41 & 0.39 & 0.22 & & & & 0.73 & 0.66 & 0.82 & 0.66 & 0.66 & 0.87 & 0.63 & 0.87 & 0.75 & 0.3 & 0.59 & 0.51 \\
\hline \multirow[t]{2}{*}{$\tau_{3}$} & -0.69 & -0.47 & -0.27 & -0.84 & -0.52 & 1 & - & - & - & 0.86 & -0.66 & 0.7 & -0.8 & -0.91 & 0.29 & -0.8 & 0.31 & 0.68 & -0.87 & -0.34 & 0.83 \\
\hline & 0.37 & 0.48 & 0.65 & 0.33 & 0.42 & 0.13 & & & & 0.35 & 0.72 & 0.61 & 0.52 & 0.48 & 0.86 & 0.52 & 0.85 & 0.73 & 0.44 & 0.8 & 0.44 \\
\hline \multirow[t]{2}{*}{$\tau_{4}$} & -0.68 & -0.61 & 0.09 & -0.87 & -0.92 & 1 & - & - & - & - & - & - & - & - & - & - & - & - & - & - & - \\
\hline & 0.32 & 0.47 & 0.61 & 0.35 & 0.29 & 0.27 & & & & & & & & & & & & & & & \\
\hline \multirow[t]{2}{*}{$\tau_{5}$} & -0.68 & -0.69 & 0.11 & -0.85 & -0.95 & 0.97 & - & - & - & - & - & - & - & - & - & - & - & - & - & - & - \\
\hline & 0.32 & 0.45 & 0.55 & 0.34 & 0.37 & 0.17 & & & & & & & & & & & & & & & \\
\hline$J$ & 45 & 37 & 39 & 37 & 36 & 34 & - & - & - & 27 & 18 & 22 & 22 & 25 & 32 & 28 & 22 & 25 & 15 & 28 & 34 \\
\hline$\|\boldsymbol{\tau}\|_{\infty}$ & 0.69 & 0.69 & 0.00 & 0.87 & 0.95 & 1.00 & - & - & & 0.86 & 0.94 & 0.70 & 0.80 & 0.91 & 0.00 & 080 & 0.00 & 0.00 & 0.92 & 0.74 & 0.83 \\
\hline
\end{tabular}

Note: The table reports Komunjer and Owyang (2012) GMM estimation results for multivariate loss functions using $d=N+1$ instruments. $\boldsymbol{\tau}_{\mathrm{j}}, \mathrm{j}=1, \ldots, 5$ denotes the loss function parameter corresponding to futures contract maturity $\mathrm{j}$. Bold numbers denote statistical significance in at least $10 \%$ level. The numbers below the estimated parameters are standard errors. The second row denotes estimation periods, (1) 2001-2004, (2) 2005-2008, (3) 2009-2013. J statistic is $X^{2}$ distributed with N(D-1) degrees of freedom. The $X^{2}$ critical values for 9 , 16 and 25 degrees of freedom at $5 \%(1 \%)$ level are 16.92 (21.67), 26.30 (32) and 37.20 (44) respectively. 
Table 12. Periodic Loss Function Estimation, Energy, 2001-2004, 2005-2008, 2009-2013

\begin{tabular}{|c|c|c|c|c|c|c|c|c|c|c|c|c|c|c|c|c|c|c|}
\hline & \multicolumn{3}{|c|}{ Crude Oil WTI } & \multicolumn{3}{|c|}{ Crude Oil Brent } & \multicolumn{3}{|c|}{ Gasoline } & \multicolumn{3}{|c|}{ Heating Oil } & \multicolumn{3}{|c|}{ Natural Gas } & \multicolumn{3}{|c|}{ Gas Oil } \\
\hline & 1 & 2 & 3 & 1 & 2 & 3 & 1 & 2 & 3 & 1 & 2 & 3 & 1 & 2 & 3 & 1 & 2 & 3 \\
\hline \multicolumn{19}{|c|}{ Quadratic Specification $(p=2)$} \\
\hline \multirow[t]{2}{*}{$\tau_{1}$} & -0.01 & -0.02 & -0.07 & -0.08 & -0.02 & -0.07 & 0.08 & 0.13 & 0.15 & -0.07 & -0.09 & -0.01 & 0.12 & 0.093 & 0.059 & -0.08 & -0.01 & 0.02 \\
\hline & 0.14 & 0.09 & 0.25 & 0.17 & 0.08 & 0.17 & 0.24 & 0.19 & 0.28 & 0.14 & 0.12 & 0.2 & 0.24 & 0.16 & 0.093 & 0.16 & 0.14 & 0.21 \\
\hline \multirow[t]{2}{*}{$\tau_{2}$} & -0.14 & 0.24 & -0.12 & -0.25 & 0.18 & -0.4 & -0.11 & 0.27 & -0.31 & -0.16 & 0.13 & -0.27 & 0.08 & 0.23 & 0.21 & -0.18 & 0.02 & -0.27 \\
\hline & 0.17 & 0.12 & 0.34 & 0.16 & 0.12 & 0.17 & 0.17 & 0.15 & 0.25 & 0.24 & 0.15 & 0.25 & 0.26 & 0.13 & 0.12 & 0.18 & 0.13 & 0.19 \\
\hline \multirow[t]{2}{*}{$\tau_{3}$} & -0.37 & 0.29 & -0.26 & -0.43 & 0.28 & -0.54 & -0.29 & 0.13 & -0.51 & -0.39 & 0.27 & -0.49 & -0.18 & 0.39 & 0.45 & -0.4 & 0.22 & -0.52 \\
\hline & 0.13 & 0.1 & 0.4 & 0.09 & 0.11 & 0.13 & 0.14 & 0.11 & 0.18 & 0.12 & 0.13 & 0.23 & 0.2 & 0.14 & 0.089 & 0.12 & 0.13 & 0.14 \\
\hline \multirow[t]{2}{*}{$\tau_{4}$} & -0.55 & -0.11 & -0.32 & -0.52 & -0.06 & -0.51 & -0.53 & -0.3 & -0.44 & -0.56 & -0.06 & -0.49 & -0.34 & 0.55 & 0.56 & -0.55 & 0.02 & -0.53 \\
\hline & 0.09 & 0.15 & 0.44 & 0.08 & 0.14 & 0.19 & 0.061 & 0.15 & 0.2 & 0.08 & 0.18 & 0.23 & 0.18 & 0.13 & 0.047 & 0.07 & 0.16 & 0.19 \\
\hline \multirow[t]{2}{*}{$\tau_{5}$} & -0.72 & -0.54 & -0.25 & -0.68 & -0.54 & -0.43 & -0.77 & -0.57 & -0.35 & -0.71 & -0.47 & -0.37 & -0.77 & 0.56 & 0.65 & -0.68 & -0.52 & -0.36 \\
\hline & 0.09 & 0.18 & 0.57 & 0.09 & 0.19 & 0.15 & 0.08 & 0.16 & 0.2 & 0.09 & 0.19 & 0.22 & 0.11 & 0.11 & 0.088 & 0.09 & 0.2 & 0.2 \\
\hline$J$ & 32 & 39 & 37 & 38 & 40 & 38 & 35 & 36 & 41 & 33 & 42 & 37 & 36 & 33 & 36 & 33 & 39 & 39 \\
\hline$\|\boldsymbol{\tau}\|_{2}$ & 0.99 & 0.66 & 0.5 & 0.99 & 0.64 & 0.95 & 0.99 & 0.72 & 0.83 & 0.99 & 0.57 & 0.83 & 0.87 & 0.91 & 0.99 & 0.99 & 0.56 & 0.87 \\
\hline \multicolumn{19}{|c|}{ Linear Specification $(p=1)$} \\
\hline \multirow[t]{2}{*}{$\tau_{1}$} & -0.8 & -0.19 & -0.23 & -0.9 & -0.41 & -0.29 & -0.29 & -0.02 & -0.11 & 0.67 & -0.44 & -0.2 & -0.27 & 0.76 & 0.78 & -0.55 & -0.3 & -0.12 \\
\hline & 0.25 & 0.68 & 0.68 & 0.32 & 0.41 & 0.62 & 0.71 & 0.67 & 0.73 & 0.4 & 0.61 & 0.73 & 0.72 & 0.48 & 0.39 & 0.61 & 0.73 & 0.58 \\
\hline \multirow[t]{2}{*}{$\tau_{2}$} & -0.84 & 0.36 & -0.24 & -0.98 & -1.2 & -0.6 & -0.66 & -0.45 & -0.53 & -1.4 & -0.54 & -0.45 & -0.85 & 0.91 & 1 & -0.79 & -0.51 & -0.46 \\
\hline & 0.35 & 0.46 & 0.68 & 0.16 & 0.12 & 0.61 & 0.47 & 0.53 & 0.64 & 0.7 & 0.42 & 0.67 & 0.48 & 0.27 & 0.12 & 0.46 & 0.52 & 0.52 \\
\hline \multirow[t]{2}{*}{$\tau_{3}$} & -0.98 & -0.65 & -0.46 & -1 & -1.6 & -0.4 & -0.72 & -0.78 & -0.72 & 2 & -0.84 & -0.15 & -0.87 & 0.93 & 1 & -0.84 & -0.78 & -0.38 \\
\hline & $\begin{array}{c}0.01 \\
2\end{array}$ & 0.46 & 0.6 & 0.05 & 0.07 & 0.52 & 0.42 & 0.45 & 0.5 & 0.43 & 0.43 & 0.64 & 0.44 & 0.28 & 0.06 & 0.4 & 0.52 & 0.52 \\
\hline \multirow[t]{2}{*}{$\tau_{4}$} & -0.98 & -0.65 & -0.4 & -1 & -1.6 & -0.66 & -0.91 & -0.82 & -0.75 & -0.07 & -0.94 & -0.59 & -0.85 & 0.97 & 0.96 & -0.92 & -0.88 & -0.82 \\
\hline & 0.01 & 0.46 & 0.69 & 0.05 & 0.07 & 0.4 & 0.28 & 0.45 & 0.51 & 0.01 & 0.3 & 0.5 & 0.47 & 0.1 & 0.07 & 0.28 & 0.39 & 0.4 \\
\hline \multirow[t]{2}{*}{$\tau_{5}$} & -0.98 & -0.65 & -0.28 & -1 & -1.6 & -0.51 & -0.87 & -0.79 & -0.69 & -0.06 & -0.76 & -0.49 & -0.87 & 0.96 & 1 & -0.91 & -0.82 & -0.65 \\
\hline & 0.01 & 0.46 & 0.78 & 0.05 & 0.07 & 0.57 & 0.28 & 0.44 & 0.58 & 0.01 & 0.36 & 0.62 & 0.44 & 0.1 & 0.01 & 0.27 & 0.39 & 0.57 \\
\hline$J$ & 49 & 110 & 33 & 84 & 39 & 34 & 30 & 29 & 32 & 47 & 37 & 37 & 33 & 43 & 49 & 33 & 33 & 31 \\
\hline$\|\boldsymbol{\tau}\|_{\infty}$ & 0.98 & 0.65 & 0.00 & 1.00 & 1.60 & 0.66 & 0.91 & 0.82 & 0.75 & 2.00 & 0.94 & 0.59 & 0.87 & 0.97 & 1.00 & 0.92 & 0.88 & 0.82 \\
\hline
\end{tabular}

Note: The table reports Komunjer and Owyang (2012) GMM estimation results for multivariate loss functions using $d=N+1$ instruments. $\boldsymbol{\tau}_{\mathrm{j}}, \mathrm{j}=1, \ldots, 5$ denotes the loss function parameter corresponding to futures contract maturity j. Bold numbers denote statistical significance in at least $10 \%$ level. The numbers below the estimated parameters are standard errors. The second row denotes estimation periods, (1) 2001-2004, (2) 2005-2008, (3) 2009-2013. J statistic is $X^{2}$ distributed with N(D-1) degrees of freedom. The $X^{2}$ critical values for 9,16 and 25 degrees of freedom at 5\% (1\%) level are 16.92 (21.67), 26.30 (32) and 37.20 (44) respectively. 
Table 13. Periodic Loss Function Estimation, Industrial Metals, 2001-2004, 2005-2008, 2009-2013

\begin{tabular}{|c|c|c|c|c|c|c|c|c|c|c|c|c|c|c|c|c|c|c|}
\hline & \multicolumn{3}{|c|}{ Aluminium } & \multicolumn{3}{|c|}{ Copper } & \multicolumn{3}{|c|}{ Lead } & \multicolumn{3}{|c|}{ Nickel } & \multicolumn{3}{|c|}{ Zinc } & \multicolumn{3}{|c|}{ Tin } \\
\hline & 1 & 2 & 3 & 1 & 2 & 3 & 1 & 2 & 3 & 1 & 2 & 3 & 1 & 2 & 3 & 1 & 2 & 3 \\
\hline \multicolumn{19}{|c|}{ Quadratic Specification $(p=2)$} \\
\hline \multirow[t]{2}{*}{$\tau_{1}$} & -0.04 & -0.05 & 0.2 & -0.05 & 0.01 & -0.01 & -0.03 & -0.08 & 0.03 & -0.11 & 0.06 & 0.11 & 0.02 & 0.06 & -0.01 & 0.01 & -0.05 & -0.01 \\
\hline & 0.26 & 0.1 & 0.19 & 0.17 & 0.078 & 0.13 & 0.16 & 0.07 & 0.16 & 0.16 & 0.15 & 0.28 & 0.15 & 0.19 & 0.21 & 0.11 & 0.13 & 0.15 \\
\hline \multirow[t]{2}{*}{$\tau_{2}$} & -0.22 & 0.22 & 0.18 & -0.34 & -0.02 & -0.12 & -0.27 & -0.13 & -0.05 & -0.2 & 0.16 & 0.3 & 0.09 & 0.28 & 0.01 & -0.06 & -0.08 & -0.13 \\
\hline & 0.25 & 0.09 & 0.24 & 0.17 & 0.11 & 0.14 & 0.16 & 0.11 & 0.18 & 0.16 & 0.21 & 0.32 & 0.18 & 0.2 & 0.32 & 0.18 & 0.18 & 0.2 \\
\hline \multirow[t]{2}{*}{$\tau_{3}$} & -0.42 & 0.36 & -0.09 & -0.45 & -0.15 & -0.33 & -0.44 & -0.21 & -0.35 & -0.41 & 0.14 & 0.09 & 0.24 & -0.01 & -0.18 & -0.21 & -0.15 & -0.36 \\
\hline & 0.26 & 0.10 & 0.29 & 0.17 & 0.09 & 0.16 & 0.11 & 0.11 & 0.21 & 0.12 & 0.21 & 0.28 & 0.14 & 0.18 & 0.38 & 0.17 & 0.11 & 0.16 \\
\hline \multirow[t]{2}{*}{$\tau_{4}$} & -0.37 & -0.08 & 0.21 & -0.43 & -0.55 & -0.45 & -0.55 & -0.52 & -0.63 & -0.57 & 0.01 & 0.04 & 0.54 & -0.29 & -0.46 & -0.49 & -0.39 & -0.58 \\
\hline & 0.26 & 0.15 & 0.27 & 0.15 & 0.078 & 0.17 & 0.08 & 0.11 & 0.15 & 0.12 & 0.18 & 0.42 & 0.08 & 0.18 & 0.34 & 0.12 & 0.11 & 0.11 \\
\hline \multirow[t]{2}{*}{$\tau_{5}$} & -0.49 & -0.56 & 0.2 & -0.45 & -0.75 & -0.76 & -0.57 & -0.77 & -0.61 & -0.67 & -0.31 & 0.57 & 0.69 & -0.59 & -0.47 & -0.71 & -0.77 & -0.71 \\
\hline & 0.33 & 0.16 & 0.33 & 0.27 & 0.06 & 0.1 & 0.15 & 0.06 & 0.21 & 0.11 & 0.22 & 0.3 & 0.14 & 0.2 & 0.51 & 0.14 & 0.08 & 0.11 \\
\hline$J$ & 36 & 35 & 41 & 37 & 40 & 34 & 36 & 41 & 35 & 33 & 39 & 39 & 38 & 41 & 36 & 33 & 41 & 33 \\
\hline$\|\boldsymbol{\tau}\|_{2}$ & 0.77 & 0.7 & 0.41 & 0.85 & 0.94 & 0.95 & 0.95 & 0.96 & 0.95 & 0.99 & 0.38 & 0.66 & 0.91 & 0.71 & 0.68 & 0.89 & 0.88 & 0.99 \\
\hline \multicolumn{19}{|c|}{ Linear Specification $(p=1)$} \\
\hline \multirow[t]{2}{*}{$\tau_{1}$} & -0.49 & -0.02 & 0.52 & -0.91 & -0.22 & 0.25 & -0.46 & -4.8 & -0.59 & -0.62 & -0.19 & 0.2 & 0.07 & 0.36 & 0.13 & -0.75 & 7.2 & -0.43 \\
\hline & 0.62 & 0.67 & 0.63 & 0.26 & 0.56 & 0.71 & 0.68 & 0.42 & 0.53 & 0.76 & 0.56 & 0.8 & 0.6 & 0.51 & 0.64 & 0.43 & 0.49 & 0.68 \\
\hline \multirow[t]{2}{*}{$\tau_{2}$} & -0.42 & 0.15 & 0.66 & -0.95 & -0.77 & -0.18 & -0.82 & -3.6 & -0.75 & -0.87 & 0.12 & 0.53 & 0.18 & 0.45 & 0.18 & -0.91 & 1.7 & -0.72 \\
\hline & 0.48 & 0.52 & 0.46 & 0.28 & 0.38 & 0.72 & 0.4 & 0.26 & 0.52 & 0.37 & 0.51 & 0.69 & 0.47 & 0.51 & 0.67 & 0.27 & 0.058 & 0.5 \\
\hline \multirow[t]{2}{*}{$\tau_{3}$} & -0.77 & -0.29 & 0.64 & -0.95 & -0.96 & -0.72 & -0.89 & -4.6 & -0.89 & -0.83 & 0.12 & -0.14 & 0.17 & 0.15 & -0.26 & -0.99 & -1.7 & -0.98 \\
\hline & 0.62 & 0.47 & 0.5 & 0.24 & 0.16 & 0.46 & 0.24 & 0.3 & 0.44 & 0.38 & 0.51 & 0.41 & 0.49 & 0.31 & 0.74 & 0.21 & 0.01 & 0.18 \\
\hline \multirow[t]{2}{*}{$\tau_{4}$} & -0.61 & -0.4 & 0.69 & -0.95 & -0.97 & -0.75 & -0.88 & -2.9 & -0.98 & -0.99 & 0.11 & -0.11 & 0.6 & -0.04 & -0.36 & -0.96 & -1.8 & -0.98 \\
\hline & 0.55 & 0.51 & 0.46 & 0.25 & 0.15 & 0.44 & 0.24 & 0.1 & 0.38 & 0.15 & 0.52 & 0.62 & 0.41 & 0.31 & 0.72 & 0.23 & 0.01 & 0.16 \\
\hline \multirow[t]{2}{*}{$\tau_{5}$} & -0.61 & -0.66 & 0.69 & -0.96 & -0.97 & -0.72 & -0.88 & -2.9 & -0.92 & -0.99 & 0.07 & 0.01 & 0.6 & -0.06 & -0.22 & -1 & -2.8 & -0.97 \\
\hline & 0.55 & 0.42 & 0.46 & 0.24 & 0.15 & 0.49 & 0.24 & 0.1 & 0.45 & 0.15 & 0.52 & 0.63 & 0.41 & 0.31 & 0.68 & 0.21 & 0.01 & 0.29 \\
\hline$J$ & 39 & 40 & 44 & 36 & 48 & 36 & 44 & 48 & 31 & 120 & 49 & 44 & 48 & 48 & 34 & 31 & 21 & 33 \\
\hline$\|\boldsymbol{\tau}\|_{\infty}$ & 0.77 & 0.66 & 0.69 & 0.96 & 0.97 & 0.75 & 0.89 & 4.8 & 0.98 & 0.99 & 0.00 & 0.00 & 0.60 & 0.00 & 0.00 & 1.00 & 7.2 & 0.98 \\
\hline
\end{tabular}

Note: The table reports Komunjer and Owyang (2012) GMM estimation results for multivariate loss functions using $d=N+1$ instruments. $\boldsymbol{\tau}_{\mathbf{j}}, \mathrm{j}=1, \ldots, 5$ denotes the loss function parameter corresponding to futures contract maturity $\mathrm{j}$. Bold numbers denote statistical significance in at least $10 \%$ level. The numbers below the estimated parameters are standard errors. The second row denotes estimation periods, (1) 2001-2004, (2) 2005-2008, (3) 2009-2013. J statistic is $X^{2}$ distributed with N(D-1) degrees of freedom. The $X^{2}$ critical values for 9,16 and 25 degrees of freedom at 5\% (1\%) level are 16.92 (21.67), 26.30 (32) and 37.20 (44) respectively. 
Table 14. Periodic Loss Function Estimation, Precious Metals, 2001-2004, 2005-2008, 2009-2013

\begin{tabular}{|c|c|c|c|c|c|c|c|c|c|c|c|c|}
\hline & \multicolumn{3}{|c|}{ Gold } & \multicolumn{3}{|c|}{ Silver } & \multicolumn{3}{|c|}{ Platinum } & \multicolumn{3}{|c|}{ Palladium } \\
\hline & 1 & 2 & 3 & 1 & 2 & 3 & 1 & 2 & 3 & 1 & 2 & 3 \\
\hline \multirow[t]{2}{*}{$\tau_{1}$} & -0.22 & -0.15 & -0.09 & -0.37 & -0.01 & -0.06 & -0.11 & -0.24 & 0.029 & 0.17 & -0.17 & -0.06 \\
\hline & 0.15 & 0.15 & 0.14 & 0.2 & 0.21 & 0.18 & 0.55 & 0.7 & 0.76 & 0.59 & 0.89 & 0.66 \\
\hline \multirow[t]{2}{*}{$\tau_{2}$} & -0.34 & -0.35 & -0.16 & -0.5 & -0.03 & -0.09 & -0.9 & -0.83 & -0.21 & 0.82 & 0.19 & -0.54 \\
\hline & 0.21 & 0.15 & 0.18 & 0.21 & 0.2 & 0.22 & 0.31 & 0.4 & 1.1 & 0.43 & 1.2 & 0.87 \\
\hline \multirow[t]{2}{*}{$\tau_{3}$} & -0.44 & -0.51 & -0.36 & -0.39 & 0.03 & -0.34 & - & - & - & - & - & - \\
\hline & 0.18 & 0.16 & 0.14 & 0.16 & 0.22 & 0.18 & & & & & & \\
\hline \multirow[t]{2}{*}{$\tau_{4}$} & -0.48 & -0.51 & -0.54 & -0.35 & -0.26 & -0.52 & - & - & - & - & - & - \\
\hline & 0.15 & 0.11 & 0.12 & 0.21 & 0.18 & 0.11 & & & & & & \\
\hline \multirow[t]{2}{*}{$\tau_{5}$} & -0.63 & -0.53 & -0.73 & -0.02 & -0.63 & -0.76 & - & - & - & - & - & - \\
\hline & 0.16 & 0.13 & 0.1 & 0.29 & 0.18 & 0.13 & & & & & & \\
\hline$J$ & 38 & 40 & 31 & 38 & 39 & 34 & 7 & 5.8 & 5.1 & 14 & 13 & 5.8 \\
\hline$\|\boldsymbol{\tau}\|_{2}$ & 0.99 & 0.97 & 0.99 & 0.82 & 0.69 & 0.99 & 0.9 & 0.86 & 0.21 & 0.84 & 0.26 & 0.55 \\
\hline \multirow[t]{2}{*}{$\tau_{1}$} & -0.92 & -0.34 & -0.66 & -2.1 & -0.47 & -0.79 & -0.42 & -0.2 & -0.11 & 0.19 & -0.11 & -0.45 \\
\hline & 0.24 & 0.7 & 0.33 & 0.51 & 0.66 & 0.49 & 0.92 & 0.95 & 0.99 & 0.97 & 0.98 & 0.9 \\
\hline \multirow[t]{2}{*}{$\tau_{2}$} & -0.9 & -0.85 & -0.94 & -2 & -0.86 & -0.7 & -0.88 & -0.69 & -0.31 & 0.59 & 0.01 & -0.35 \\
\hline & 0.22 & 0.43 & 0.15 & 0.44 & 0.44 & 0.65 & 0.48 & 0.62 & 0.94 & 0.8 & 0.99 & 0.92 \\
\hline \multirow[t]{2}{*}{$\tau_{3}$} & -0.92 & -0.87 & -0.99 & -1.2 & -0.79 & -0.79 & - & - & - & - & - & - \\
\hline & 0.17 & 0.46 & 0.08 & 0.65 & 0.52 & 0.45 & & & & & & \\
\hline \multirow[t]{2}{*}{$\tau_{4}$} & -0.97 & -0.87 & -0.99 & -3.2 & -0.84 & -0.85 & - & - & - & - & - & - \\
\hline & 0.081 & 0.3 & 0.1 & 0.03 & 0.39 & 0.39 & & & & & & \\
\hline \multirow[t]{2}{*}{$\tau_{5}$} & -0.97 & -0.96 & -0.99 & -3.2 & -0.84 & -0.97 & - & - & - & - & - & - \\
\hline & 0.08 & 0.15 & 0.08 & 0.03 & 0.39 & 0.28 & & & & & & \\
\hline$J$ & 39 & 34 & 29 & 54 & 32 & 33 & 8.3 & 8.9 & 13 & 15 & 12 & 19 \\
\hline$\|\boldsymbol{\tau}\|_{\infty}$ & 0.97 & 0.96 & 0.99 & 3.2 & 0.86 & 0.97 & 0.88 & 0.00 & 0.00 & 0.00 & 0.00 & 0.00 \\
\hline
\end{tabular}

Note: The table reports Komunjer and Owyang (2012) GMM estimation results for multivariate loss functions using $d=N+1$ instruments. $\boldsymbol{\tau}_{\mathrm{j}}, \mathrm{j}=1, \ldots, 5$ denotes the loss function parameter corresponding to futures contract maturity $\mathrm{j}$. Bold numbers denote statistical significance in at least $10 \%$ level. The numbers below the estimated parameters are standard errors. The second row denotes estimation periods, (1) 2001-2004, (2) 2005-2008, (3) 2009-2013. J statistic is $\mathrm{X}^{2}$ distributed with N(D-1) degrees of freedom. The $\mathrm{X}^{2}$ critical values for 9,16 and 25 degrees of freedom at $5 \%(1 \%)$ level are 16.92 (21.67), 26.30 (32) and 37.20 (44) respectively. 
Graph 2. Temporal Evolution of Futures Curves and Preferences

(a) Natural Gas 2001-2004 Natural Gas 2005-2008 Natural Gas 2009-2013

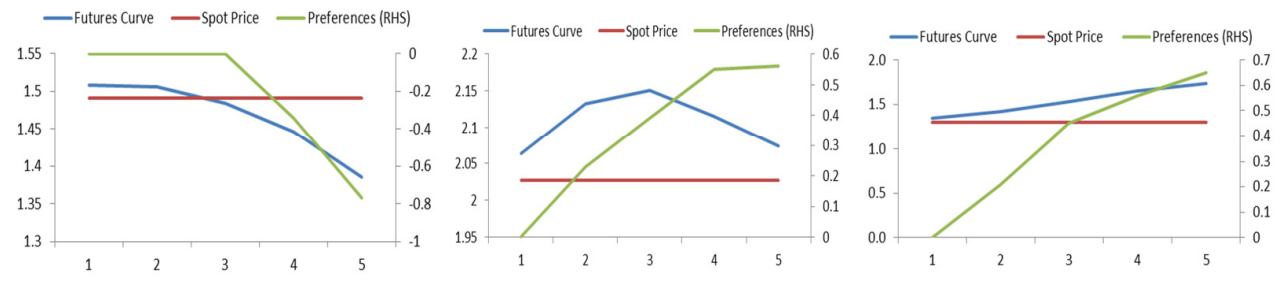

(b) Nickel 2001-2004

Nickel 2005-2008

Nickel 2009-2013

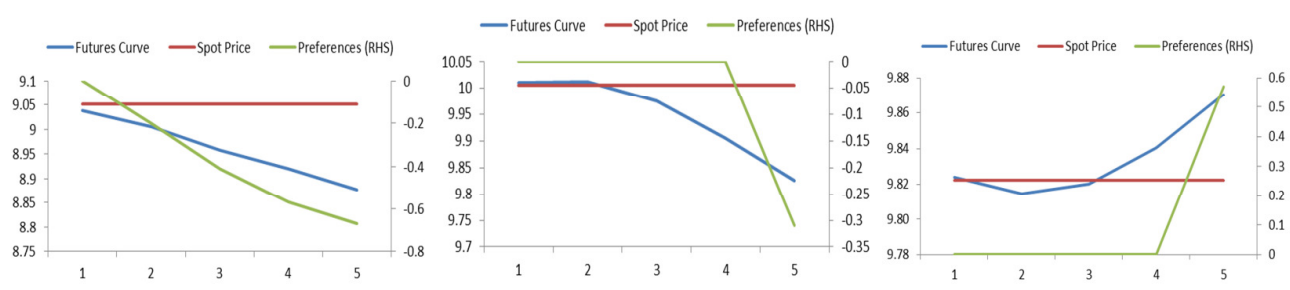

(c) Coffee 2001-2004

Coffee 2005-2008

Coffee 2009-2013

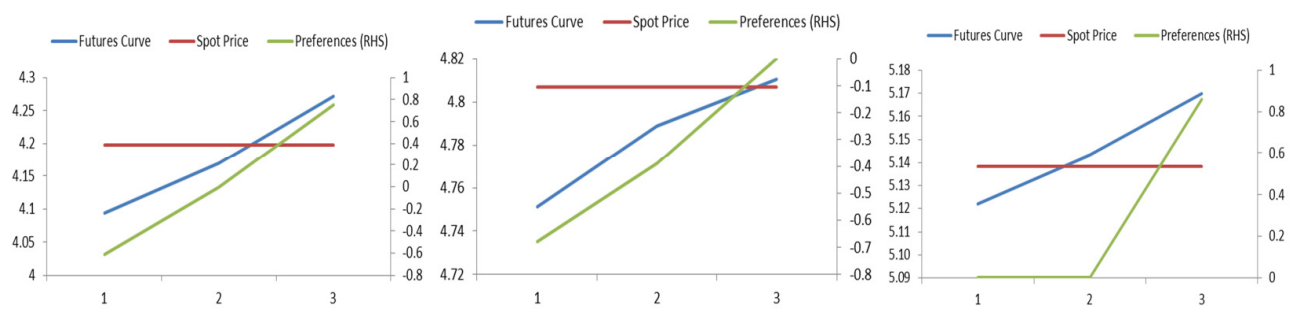

(d) Lean Hogs 2001-2004 Lean Hogs 2005-2008 Lean Hogs 2009-2013

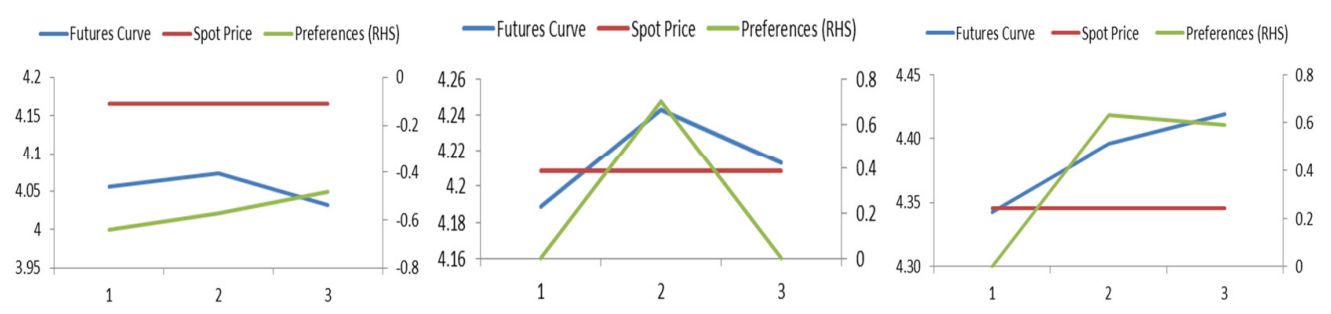

(e) Gold 2001-2004

Gold 2005-2008

Gold 2009-2013

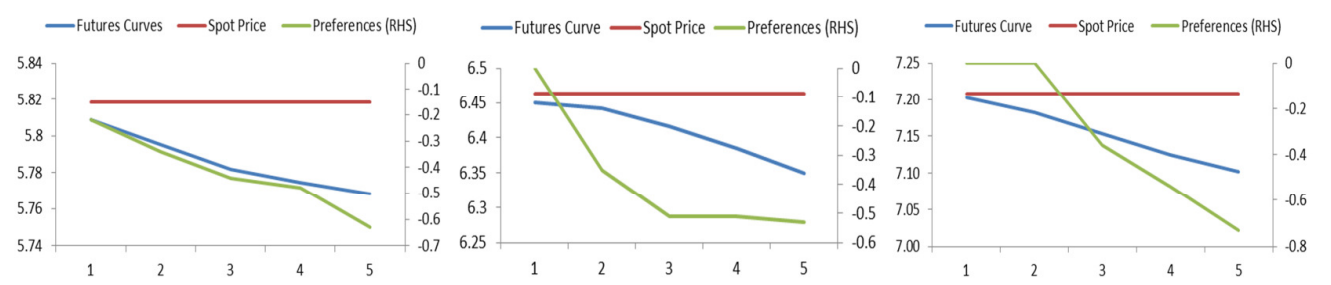




\section{Concluding Remarks}

We suggest going beyond the standard approach in the literature, which links commodity market efficiency to predictability and teststhe relationship between current futures contract price and the commodity spot price in the future using univariate linear regression. This conventional framework reflects symmetric preferences and fails to account for preference asymmetries as well as for the dependence between price forecast errors of different maturities i.e. along the futures curve, thus often falsely concluding the presence or the absence of market inefficiency or forecast irrationality. Instead, in this paper we view the futures curve as a jointly determined market path forecast and estimate the term structure of joint market preferences under flexible multivariate asymmetric loss and test for forecast rationality using the GMM procedure proposed by Komunjer and Owyang (2012).

We consider the universe of thirty commodities composing the six major commodity futures indexes, for maturities from 1- to 12-months, subject to sufficient trading volume from 2001 to 2013, covering a broad crisis period. These commodities are classified in five sectors, namely agriculture, livestock, energy, industrial metals and precious metals. Our fullsample empirical evidence reveals generally term structures of preferences in which short maturities usually appear with symmetric preferences and longer maturities appear with asymmetric preferences. Preference asymmetries are more often optimistic and across all five commodity sectors, while they appear as prudent in a small number of cases in agriculture and for Natural Gas. Moreover, we observe symmetric preference term structures in eight cases and fully prudent or optimistic preferences in one case respectively. Motivated by the presence of a number of non-significant preference asymmetries in our full sample analysis, along with large parameter standard errors, we apply the procedure proposed by Giacomini and Rossi (2009) to test for the presence of price forecast breakdowns. A forecast breakdown may be due to various factors including changes in preferences. Our evidence suggests that for most commodities breakdowns take place during the first and the last four years of our study period, thus leading to three sequential non-overlapping four-year sup-periods of rotating price forecast (in) stability. Guided by this evidence, we re-estimated multivariate market loss preferences in the three sequential sub-periods. Our periodic evidence reveals the presence of overall optimistic preferences for most commodities in sub-period 2001-2004, evolving into oscillating preferences in sub-period 2005-2008 rotating within the term structure from symmetry to pessimism and optimism, and finally back to general optimism in sub-period 2009-2013 but in a smaller number of commodities. These shapes may reflect the 
varying presence of index traders who counterbalance the effects of hedgers in determining the shape of the futures curves, see van Huellen (2019).

This paper contributes to the literature a novel approach to address the market joint preferences along the commodity futures curve and provides supportive empirical evidence for the most heavily traded global commodities. Forecast rationality tests show that our framework accommodates the rationality of observed forecast errors and thus serves as a new approach for the advancement of forecasting and trading in commodity markets.

\section{References}

Alghalith M (2010), Preferences estimation without approximation, European Journal of Operational Research, 207, pp. 1144-1146

Alquist,R and Kilian,L (2010), What do we learn from the price of crude oil futures? Journal of Applied Econometrics, 25, 539-573

Bakshi G, X Gao and A Rossi (2019), Understanding the Sources of Risk Underlying the Cross Section of Commodity Returns, Management Science, Vol 65 (2), 619-641

Bernanke B (2008), Outstanding Issues in the Analysis of Inflation, Keynote Address, 53 ${ }^{\text {rd }}$ Annual Economic Conference, Federal Reserve Bank of Boston, Chatham, Massachusetts

Blackmond-Laskey K and G Fischer (1987), Estimating Utility Functions in the Presence of Response Error, Management Science, 33 (8), pp. 965-980

Brenner S (2015), The Risk Preferences of U.S. Executives, Management Science, 61 (6), pp. $1344-1361$

Brenner, R. and Kroner,K. (1995), Arbitrage, cointegration and testing the unbiasedness hypothesis in financial markets, Journal of Financial and Quantitative Analysis, 30, 23-42

Carter, C. A., Rausser, G. C. and Schmitz, A. (1983), Efficient asset portfolios and the theory of normal backwardation, Journal of Political Economy, 91 (3), 19-31

ChenY-C., Rogoff,K. and Rossi,B. (2009), Can exchange rates forecast commodity prices? Quarterly Journal of Economics, 125, 1145-1194

Chen, Yuchin and Kwok Ping Tsang (2013), What Does the Yield Curve Tell Us About Exchange Rate Predictability?, Review of Economics and Statistics, 95, 1, 185-205

Christodoulakis G and E Mamatzakis (2009), Assessing the Prudence of Economic Forecasts in the EU, Journal of Applied Econometrics, 24, 583 - 606

Christoffersen, P and Diebold, F (1997), Optimal Prediction Under Asymmetric Loss, Econometric Theory, 13, 6, 808-817

Credit Suisse (2012). Global Investment Returns Yearbook.

De los Rios, Antonio Diez (2009), Can Affine Term Structure Models Help Us Predict Exchange Rates?, Journal of Money, Credit and Banking, 41, 4, 755-766. 
Elliott, G., Komunjer, I. and A. Timmermann (2005), Estimation and Testing for Forecast Rationality under Flexible Loss, Review of Economic Studies, 72, 4, 1107-1125

Elliott, G., Komunjer, I. and Timmermann, A. (2008), Biases in Macroeconomic Forecasts: irreationality or Asymmetric Loss?, Journal of the European Economic Association, 6, 122157

Fama E and K French (1987), Commodity Futures Prices: Some Evidence on Forecast Power, Premiums, and the Theory of Storage, Journal of Business, 60, 1, 55-73

Fattouh B, L. Kilian, and L. Mahadeva. The role of speculation in oil markets: What have we learned so far? CEPR Discussion Papers 8916, C.E.P.R. Discussion Paper Series

Feess E, H Müller and C Schumacher (2016), Estimating risk preferences of bettors with different bet sizes, European Journal of Operational Research, 249, pp. 1102-1112

French K (1986), Detecting Spot Price Forecasts In Futures Prices, Journal of Business, 59, 2, S39-S54

Giacomini R. and B Rossi (2009), Detecting and Predicting Forecast Breakdown, Review of Economic Studies, 76(2), 669-705

Gorton G and K. G. Rouwenhorst (2006). Facts and fantasies about commodity futures, Financial Analysts Journal, 62, 2, 47-68

Goyal A and I Welch, (2003) Predicting the Equity Premium with Dividend Ratios. Management Science, 49 (5), pp. 639-654

Granger C W J and M Machina (2006), Forecasting and Decision Theory, in Elliott G, Granger C W J and A Timmermann eds., Handbook of Economic Forecasting, Vol 1, pp 8198

Halme M and Kallio (2014), Likelihood estimation of consumer preferences in choice-based conjoint analysis, European Journal of Operational Research, 239, 556-564

Hamilton, J. D. (2009), Causes and consequences of the oil shock of 2007-08, Brookings Papers on Economic Activity, Spring, 215-259

Hamilton J and S Wu (2015), Effects of Index-Fund Investing on Commodity Futures Prices, International Economic Review, 56 (1), pp. 187-205

Hong $\mathrm{H}$ and $\mathrm{M}$ Yogo (2012), What does futures market interest tell us about the macroeconomy and asset prices?, Journal of Financial Economics, 105, 473-490

Hazuka, T. B. (1984), Consumption betas and backwardation in commodity markets, Journal of Finance, 39, 647-55.

Inci Ahmet Can, Lu Biao (2004), Exchange rates and interest rates: Can term structure models explain currency movements?, Journal of Economic Dynamics and Control, 28, 8, $1595-1624$

Jarrow R and F Zhao, (2006), Downside Loss Aversion and Portfolio Management, Management Science, 52 (4) pp. 558-566 
Jordà O and M Marcellino (2010), Path Forecast Evaluation, Journal of Applied Econometrics, 25, 635-662

Joëts M (2015), Heterogeneous beliefs, regret, and uncertainty: The role of speculation in energy price dynamics, European Journal of Operational Research, 247, pp. 204-215

Komunjer, I and M Owyang, (2012), Multivariate Forecast Evaluation and Rationality Testing, Review of Economics and Statistics, 94(4): 1066-1080

Laws J and J Thompson (2004), The efficiency of financial futures markets: Tests of prediction accuracy, European Journal of Operational Research, 155, pp. 284-298

Menezes L de, D Bunn and J Taylor (2000), Review of guidelines for the use of combined forecasts, European Journal of Operational Research, 120, pp. 190-204

Murphy R and R ten Brincke (2018), Hierarchical Maximum Likelihood Parameter Estimation for Cumulative Prospect Theory: Improving the Reliability of Individual Risk Parameter Estimates, Management Science, Vol. 64(1), 308 - 326

Nixon D and T Smith (2012), What can oil futures curve tell us about the outlook for oil prices?, Quarterly Bulletin, Q1, 39-47, Bank of England

Paravisini D, V Rappoport and E Ravina (2017), Risk Aversion and Wealth: Evidence from Person-to-Person Lending Portfolios, Management Science, 63 (2), pp. 279-297

Pennings J and A Smidts (2000), Assessing the Construct Validity of Risk Attitude, Management Science, 46 (10) pp. 1337-1348

Pennings J and A Smidts (2003), The Shape of Utility Functions and Organizational Behavior, Management Science, 49 (9), pp. 1251-1263.

Reeve T and R Vigfusson (2011), Evaluating the Forecasting Performamnce of Commodity Futures Prices, Discussion Paper 1025, Board of Governors of the Federal Reserve System

Singleton K (2014), Investor Flows and the 2008 Boom/Bust in Oil Prices, Management Science, 60 (2), pp. 300-318

UNCTAD (2011), Price Formation in Financialized Commodity Markets: the role of information, Special Report, United Nations Conference on Trade and Development, Geneva

UNCTAD (2009), Development Impacts of Commodity Exchanges in Emerging Markets, Special Report, United Nations Conference on Trade and Development, Geneva

Van Heullen S (2019), Too much of a good thing? Speculative effects on commodity futures curves, Journal of Financial Markets, forthcoming

Yang F (2013), Investment shocks and the commodity basis spread, Journal of Financial Economics, 110, 164-184

Wakker P and D Deneffe (1996), Eliciting von Neumann-Morgenstern Utilities When Probabilities are Distorted or Unknown, Management Science, 42 (8), pp. 1131-1150

Wolfers J and E Zitzewitz (2004), Prediction Markets, Journal of Economic Perspectives, Vol. 18, No. 2, pp. 107-126 